\title{
Attribution and Impacts of Upper-Ocean Biases in CCSM3
}

\author{
W. G. Large and G. Danabasoglu \\ National Center for Atmospheric Research,* Boulder, Colorado
}

(Manuscript received 16 December 2004, in final form 21 October 2005)

\begin{abstract}
The largest and potentially most important ocean near-surface biases are examined in the Community Climate System Model coupled simulation of present-day conditions. They are attributed to problems in the component models of the ocean or atmosphere, or both. Tropical biases in sea surface salinity (SSS) are associated with precipitation errors, with the most striking being a band of excess rainfall across the South Pacific at about $8^{\circ} \mathrm{S}$. Cooler-than-observed equatorial Pacific sea surface temperature (SST) is necessary to control a potentially catastrophic positive feedback, involving precipitation along the equator. The strength of the wind-driven gyres and interbasin exchange is in reasonable agreement with observations, despite the generally too strong near-surface winds. However, the winds drive far too much transport through Drake Passage [ $\left.>190 \mathrm{~Sv}\left(1 \mathrm{~Sv} \equiv 10^{6} \mathrm{~m}^{3} \mathrm{~s}^{-1}\right)\right]$, but with little effect on SST and SSS. Problems with the width, separation, and location of western boundary currents and their extensions create large correlated SST and SSS biases in midlatitudes. Ocean model deficiencies are suspected because similar signals are seen in uncoupled ocean solutions, but there is no evidence of serious remote impacts. The seasonal cycles of SST and winds in the equatorial Pacific are not well represented, and numerical experiments suggest that these problems are initiated by the coupling of either or both wind components. The largest mean SST biases develop along the eastern boundaries of subtropical gyres, and the overall coupled model response is found to be linear. In the South Atlantic, surface currents advect these biases across much of the tropical basin. Significant precipitation responses are found both in the northwest Indian Ocean, and locally where the net result is the loss of an identifiable Atlantic intertropical convergence zone, which can be regained by controlling the coastal temperatures and salinities. Biases off South America and Baja California are shown to significantly degrade precipitation across the Pacific, subsurface ocean properties on both sides of the equator, and the seasonal cycle of equatorial SST in the eastern Pacific. These signals extend beyond the reach of surface currents, so connections via the atmosphere and subsurface ocean are implicated. Other experimental results indicate that the local atmospheric forcing is only part of the problem along eastern boundaries, with the representation of ocean upwelling another likely contributor.
\end{abstract}

\section{Introduction}

Numerical models of the global ocean initialized with observations inevitably develop biases, primarily because of model deficiencies and forcing errors. In fully coupled models such as the Community Climate System Model version 3 (CCSM3), the forcing problem is exacerbated by errors in the atmospheric, sea ice, and even land components that manifest themselves as

\footnotetext{
* The National Center for Atmospheric Research is sponsored by the National Science Foundation.
}

Corresponding author address: Dr. W. G. Large, National Center for Atmospheric Research, P.O. Box 3000, Boulder, CO 80307.

E-mail:wily@ncar.ucar.edu ocean surface flux error. Furthermore, the coupling of components that individually behave well may cause "coupled" errors that grow because of feedbacks between components.

Certain biases that develop in a climate model may not overly compromise either the responsible component or local region but could be catastrophic to other components and remote regions. Such possibilities become more likely as climate system models incorporate more features of the "earth system," such as carbon cycling, dynamic vegetation, and glacial evolution. Therefore, it is important to diagnose the likely sources of biases, so that the problems can be understood, prioritized, and attacked in the culpable component, or as a coupled system.

Evaluations of coupled climate models have revealed common ocean biases. An early comparison by Mechoso 
et al. (1995) found that sea surface temperature (SST) along the equator of the central Pacific became as much as $3^{\circ} \mathrm{C}$ colder than observed in 9 of 11 solutions. Similar cold biases have persisted in other models, such as the Third Hadley Centre Coupled Ocean-Atmosphere General Circulation Model (HadCM3; Gordon et al. 2000) and CCSM version 2 (CCSM2; Kiehl and Gent 2004). Both these examples also develop warm SST biases off the west coasts of South America and southern Africa. The evaluation of coupled climate models (McAvaney et al. 2001) for the Third Assessment Report of the Intergovernmental Panel on Climate Change (IPCC) reports other common biases. For example, the region of maximum SST variability associated with the El Niño-Southern Oscillation (ENSO) phenomenon is displaced westward and its strength underestimated. Also, the northward heat transport by the Atlantic across $24^{\circ} \mathrm{N}$ is less than $1 \mathrm{PW}$ in 18 of 24 models, whereas Bryden and Imawaki (2001) report a range from about 1.1 to $1.3 \mathrm{PW}$.

The specific purpose of the present work is to expose some of the largest and potentially most important biases in the CCSM3 fully coupled simulation of the present-day climate. It focuses on the upper ocean to allow a more detailed examination of the ocean that is in most direct contact with the atmosphere. Of particular interest are the attribution of biases to component models and/or coupled behavior and the assessments of remote impacts. The latter seeks errors that significantly affect extensive portions of the multicomponent solutions. The former utilizes results from the uncoupled atmosphere forced with prescribed SST and from the ocean component forced with prescribed atmospheric variables (section 2).

Sea surface salinity (SSS) biases are examined first (section 3) because of their relatively straightforward response to precipitation and important contribution to surface density, and hence to vertical transport and to ventilation of the deeper ocean. However, most attention will be focused on SST because it is the most important ocean parameter involved in coupling to the atmosphere. Section 4 considers the errors arising from model representation of ocean general circulation, and in particular of western boundary currents. Section 5 investigates the SST biases generated along the subtropical eastern boundaries of the oceans and presents results from a number of numerical experiments designed to discover their origins and impacts. Section 6 focuses on the equatorial Pacific Ocean because of the global importance of the ENSO variability initiated in this region. Concluding remarks are contained in section 7 .

\section{CCSM3 and ocean biases}

This section discusses three essential ingredients of this study of upper-ocean biases in CCSM3. First, there is an examination of how SST and SSS biases are generated in ocean models and how they relate to surface forcing. Second, the observations and global datasets that are used to determine the biases are described. Included here is a balanced surface flux dataset that at least provides an idea of what the coupled model airsea exchanges could be globally. Finally, comes a brief description of the model that generates the biases, together with the specifics of the coupled experiments and uncoupled ocean and atmosphere integrations that are used to explore them. Only the most relevant aspects of the ocean model are presented because details of the ocean and atmosphere component models are given in Danabasoglu et al. (2006) and in Collins et al. (2006b), respectively.

\section{a. Generation of SSS and SST biases}

When CCSM3 is integrated from an initial, observed ocean state, it develops biases in both SSS and SST according to

$$
\begin{gathered}
\delta S S S=-F_{S}+T_{S} \\
\delta S S T=Q_{H}+T_{H},
\end{gathered}
$$

where $T_{S}$ and $T_{H}$ include all the time-integrated, active ocean transport processes, such as advection, entrainment, mixing, and diffusion. In developing expressions for these terms (Stevenson and Niiler 1983), the heat and salt conservation equations are integrated down to an effective mixing depth, $h$, which is often, but not always, similar to the mixed layer depth. The depth $h$ must be shallow enough for the integrated salinity and temperature to be representative of SSS and SST, but deep enough for fluxes across it to represent exchanges between the ocean interior and boundary layer. It evolves in response to local vertical velocity and entrainment.

The time-integrated surface freshening, $F_{S}$, and surface heating, $Q_{H}$, on the right-hand side (rhs) of (1) are given by

$$
\begin{aligned}
F_{S} & =\frac{S_{r}}{\rho} \int_{0}^{t} \frac{F_{o}}{h} d t^{\prime} \\
Q_{H} & =\frac{1}{\rho c_{p}} \int_{0}^{t} \frac{Q_{o}(\mathrm{SST})}{h} d t^{\prime},
\end{aligned}
$$

where $\rho, c_{p}$, and $S_{r}$ are ocean density, heat capacity, and reference salinity, respectively. The net freshwater flux into the ocean, $F_{o}$, is due to precipitation, evaporation, 
runoff, and snow/ice melt or formation. The net surface heat flux, $Q_{o}$, includes short- and longwave radiation, sensible and latent heat flux, and any heat exchange between ice/snow and the ocean.

All changes in SSS and SST are due to imbalances on the rhs of (1). Seasonal cycles are dominant signals arising from the solar forcing. Biases in the seasonal evolution of $\delta$ SSS and $\delta$ SST (section 6) arise when the error in the balance of terms in (1) changes over the course of a year. Smaller year-to-year changes mostly reflect expected interannual variability in the coupled system. However, systematic errors over many years lead to the biases in the climatological mean that are investigated in sections 3,4 , and 5 . These biases arise from integrated imbalances, so small errors can become serious if they are not compensated by some negative feedback process over long time scales.

As evident from (2), SSS and SST biases develop differently, because the freshwater flux is independent of SSS, whereas SST directly affects the latent, sensible, and outgoing longwave heat fluxes. This negative feedback can be approximated by

$$
\frac{\partial Q_{o}}{\partial \mathrm{SST}}=-(5+4 U) \mathrm{W} \mathrm{m}^{-2} \mathrm{~K}^{-1},
$$

for wind speed, $U$, in meters per second, and gives a typical $30 \mathrm{~W} \mathrm{~m}^{-2}$ change in heat flux for a $1^{\circ} \mathrm{C}$ change in SST. However, in a fully coupled model there is only about half the change in $Q_{o}$ (Doney et al. 1998) because of the accompanying same sign change in near-surface air temperature.

According to (1a), a freshwater flux error would continue to generate a growing SSS bias until internal ocean salinity gradients create compensating erroneous ocean salt transport. Although SST could respond to a heat flux error in a similar fashion, the changing SST would tend to reduce the flux error according to (3). Therefore, the primary response to too much (little) ocean surface heating is often just an increase (decrease) of SST until (3) reduces (increases) $Q_{o}$, while ocean transport is little changed. Similarly, SSS and SST can respond differently to ocean transport. Heat transport errors should become balanced by unrealistic surface heat fluxes, likely involving SST biases. However, correct freshwater fluxes could be maintained despite initially incorrect transport, with salinity biases growing until the overall salt transport improves.

\section{b. Ocean observations and global datasets}

Unless otherwise indicated, observed SST refers to a recent global dataset based on a merger of an SST analysis of satellite and in situ data (Reynolds et al.
2002) after 1982, with historical SSTs reconstructed from ship observations beginning in 1871 (Rayner et al. 2003). It has been made compatible with historical sea ice distributions (J. Hurrell 2003, personal communication).

The 1998 World Ocean Atlas (WOA98) of Levitus et al. (1998) directly gives ocean temperature and salinity. To better represent the Arctic Ocean and neighboring seas, we use the Polar Science Center Hydrographic Climatology (Steele et al. 2001), which merges the WOA98 with the regional Arctic Ocean Atlas (Timokhov and Tanis 1997, 1998). The result, hereafter WOA $/ \mathrm{P}$, is a $1^{\circ}$ global climatology of monthly mean ocean temperature and salinity. These data are interpolated to the ocean model grid. Two major caveats are that large areas of the ocean are undersampled, and that the processing includes considerable horizontal averaging of observed profiles. Undesirable consequences include the creation of nonexistent water masses, gravitationally unstable density profiles, and equatorial temperatures that are too warm (cold) above (below) the undercurrent core where isotherms dome (slump).

In the equatorial Pacific, the data density has been relatively high since about 1990 . Particularly useful observed data are the direct measurements of upperocean currents, temperature, and salinity described by Johnson et al. (2002). The seasonal distribution of sampling is shown by Kessler et al. (2003), and at some longitudes it is unevenly distributed over the year.

The general circulation of the ocean most relevant to the upper ocean is characterized by the wind-driven gyre circulation, and interbasin exchanges through Drake Passage (DPT), the Indonesian Throughflow (ITF), and Bering Strait (BST). Observational estimates of the mean volume transports are DPT $=134 \pm$ $13 \mathrm{~Sv}\left(1 \mathrm{~Sv} \equiv 10^{6} \mathrm{~m}^{3} \mathrm{~s}^{-1}\right.$; Whitworth 1983; Whitworth and Peterson 1985), ITF $=10-15$ Sv (Gordon 2001), and $\mathrm{BST}=0.83 \mathrm{~Sv}$, with an interannual variability of $0.5 \mathrm{~Sv}$ (Roach et al. 1995). Measures of the strength of some ocean gyres are given in section 4. One of these, the Atlantic subtropical gyre, is fed by the Florida Strait Transport between Florida and Cuba (FCT), which closely matches the transport between Yucatan and Cuba (YCT), and is augmented by flow between the Bahamas and Cuba (BCT) to give a larger transport between Florida and the Bahamas (FBT). Observational estimates of these transports are summarized by Hamilton et al. (2005), who find FCT $\approx 25 \mathrm{~Sv}$, and quote YCT $=23.8 \pm 1 \mathrm{~Sv}$ (Sheinbaum et al. 2002), BCT $=3 \mathrm{~Sv}$ (Atkinson et al. 1995), and FBT = $30.5 \pm 1 \mathrm{~Sv}$ (Schott et al. 1988) and $32 \pm 3 \mathrm{~Sv}$ (Larsen 1992).

Satellite scatterometer [Quik Scatterometer (QSCAT)] wind fields (Chin et al. 1998, Milliff et al. 2004) are 
available since 1999 and provide global measurements of the surface wind stress on a daily basis. The wind accuracy relative to measurements from surface buoys is about $1 \mathrm{~m} \mathrm{~s}^{-1}$ in speed and $20^{\circ}$ in direction for winds less than $20 \mathrm{~m} \mathrm{~s}^{-1}$ (Ebuchi et al. 2002; Freilich and Vanhoff 2006). At wind speeds of 5,10 , and $20 \mathrm{~m} \mathrm{~s}^{-1}$, the respective uncertainty in wind stress magnitude becomes $0.015 \mathrm{~N} \mathrm{~m}^{-2}$ or $40 \%, 0.03 \mathrm{~N} \mathrm{~m}^{-2}$ or $20 \%$, and $0.06 \mathrm{~N} \mathrm{~m}^{-2}$ or $10 \%$. Not only are these measurements relatively accurate, but the frequent sampling essentially eliminates this random error from multiyear averages, especially of zonal means. The uncertainty remaining in such averages is less than $10 \%$. It stems mainly from the buoy measurements used in the calibration because the relationship of wind (relative to ocean current) to stress (drag coefficient) is much simpler with scatterometer measurements (Liu and Large 1981; Li et al. 1989).

All the surface fluxes, hereafter denoted as LY, have been computed from the ocean forcing dataset and bulk formulas methodology described in Large and Yeager (2004), plus the above observed SST, over the 17-yr period (1984-2000). The global National Centers for Environmental Prediction-National Center for Atmospheric Research (NCEP-NCAR) reanalysis (Kalnay et al. 1996) is the basis for atmospheric state. However, QSCAT winds are used to correct the wind speed, and ship and buoy measurements suggest the lowering of relative humidity by a minimum of $3 \%$ and up to $7 \%$ in midlatitudes (Large and Yeager 2004). The radiation fields are provided by the International Satellite Cloud Climatology Project (Zhang et al. 2004), reduced by $5 \%$ in the Tropics in order to be more consistent with other products in Beranger et al. (1999) and buoy observations across the tropical Atlantic and Pacific (M. Jochum 2005, personal communication). Comparisons with the Baseline Solar Radiation Network also suggest such a reduction in the Tropics (Zhang et al. 2004). The net result of these corrections is a mean air-sea heat flux over the global ocean is $1 \mathrm{~W} \mathrm{~m}^{-2}$, in accord with the $0.3 \mathrm{~W} \mathrm{~m}^{-2}$ inferred from observed changes in ocean temperatures between 1955 and 2003 (Levitus et al. 2005). The implied accuracy of the global, long-term mean does not apply to ocean regions and short time scales, where uncertainties are difficult to quantify, but could be much more than $10 \mathrm{~W} \mathrm{~m}^{-2}$.

The precipitation is a blend of multiple products: Xie and Arkin (1996) in midlatitudes, Global Precipitation Climatology Project (Huffman et al. 1997) in the Tropics and around Antarctica, and Serreze and Hurst (2000) in the Arctic. Furthermore, a global freshwater balance is achieved by multiplying this blended precipitation by 1.142 then adding $0.7 \mathrm{mg} \mathrm{m}^{-2} \mathrm{~s}^{-1}$. This bal- ance includes freshwater runoff from the land based on continental imbalances between precipitation, evaporation, and storage that is partitioned among ocean basins following B. Fekete et al. (1999, personal communication). Gauge estimates of the runoff from 275 rivers (Perry et al. 1996) are used to distribute the runoff along coasts. Based on the spread of the various datasets, the uncertainty in the precipitation is at least $\pm 10 \mathrm{mg} \mathrm{m}^{-2} \mathrm{~s}^{-1}$ even in zonal averages. The freshwater flux unit of $1 \mathrm{mg} \mathrm{m}^{-2} \mathrm{~s}^{-1} \approx 31 \mathrm{~mm} \mathrm{yr}^{-1}$ is convenient because it corresponds to about the same density flux as $1 \mathrm{~W} \mathrm{~m}^{-2}$ of heat flux.

These surface fluxes are not an observational dataset because the reanalysis product depends on the atmospheric forecast model and the data assimilation system, and the surface radiation is computed using radiative transfer models. Another issue with precipitation is that the behavior of a particular ocean model guided the above choices of precipitation datasets, but not the balancing.

\section{c. CCSM3 model configurations}

The model components coupled within CCSM3 are the Community Atmosphere Model version 3 (CAM3; Collins et al. 2006b), the Community Land Model (CLM; Dickinson et al. 2006), the Community Sea Ice Model (CSIM; Briegleb et al. 2004), and the Parallel Ocean Program (POP; Smith and Gent 2004). Here the primary CCSM3 configuration is referred to as $\mathrm{T} 85 \mathrm{x} 1$ to reflect its horizontal resolution-a T85 spectral truncation for both CAM 3 and CLM, and a nominal $1^{\circ}$ POP and CSIM, with the northern pole displaced into Greenland. The actual ocean and sea ice resolutions are $1.125^{\circ}$ in longitude and variable from $0.27^{\circ}$ (at the equator) to $0.64^{\circ}$ (far northwest Pacific) in latitude. The vertical distributions of the ocean's 40 and the atmosphere's 26 levels are shown in Yeager et al. (2006) and Collins et al. (2006b), respectively. Long coupled impact experiments were made possible only by resorting to a coarser T42 spectral truncation version of CAM3 and CLM, but with the ocean and sea ice models unchanged. Therefore, this configuration is denoted as T42x1 and is compared to T85x1 in Hack et al. (2006a).

The POP version in CCSM3 employs the Gent and McWilliams (1990) isopycnal transport parameterization with a mixing coefficient of $600 \mathrm{~m}^{2} \mathrm{~s}^{-1}$, the Large et al. (2001) anisotropic horizontal viscosity, as generalized by Smith and McWilliams (2003), the $K$-profile parameterization (KPP) of vertical mixing (Large et al. 1994), and an idealized diurnal cycle of solar forcing. This diurnal cycle, several modifications to KPP, an updated parameterization of double-diffusive mixing, and spatially varying, monthly solar absorption are dis- 
cussed in Danabasoglu et al. (2006). The two coefficients of lateral viscosity depend on the local deformation rate (Smagorinsky 1993), subject to $1000 \mathrm{~m}^{2} \mathrm{~s}^{-1}$ minima unless numerical constraints demand smaller values. In the upper ocean below the surface boundary layer the background vertical diffusivity and viscosity are 0.1 and $1.0 \mathrm{~cm}^{2} \mathrm{~s}^{-1}$, respectively. The barotropic equation is solved using an implicit free-surface formulation. The surface layer thickness may vary, but global ocean volume remains constant because the freshwater fluxes are treated as virtual salt fluxes.

The present-day control of $\mathrm{T} 85 \mathrm{x} 1$ has been integrated for more than $600 \mathrm{yr}$, and bias determination is based on years 571 to 600 , when the upper ocean has reached near equilibrium, even though most biases are almost fully developed within about 5 yr. Attribution utilizes results both from the ensemble of uncoupled CAM3 solutions forced with prescribed SST described by Hurrell et al. (2006), and from the ocean component with prescribed atmospheric and sea ice forcing. The respective solutions are denoted T85cam and x1ocn. The 43-yr x1ocn forcing cycle (1958-2000) is detailed in Large and Yeager (2004), and most x1ocn results are averages over the last $17 \mathrm{yr}$ (1984-2000) of the third forcing cycle (model years 113-129). However, the rapid spinup of the upper equatorial ocean allows x1ocn results in section 6 to be taken from the last of three 5-yr cycles (2000-2004) that utilized QSCAT winds. In section $5 \mathrm{a}$, coupled numerical experiments are designed to assess the large-scale impacts of specific biases. They include both short (15 yr) and longer (100 $\mathrm{yr}$ ) integrations using $\mathrm{T} 85 \mathrm{x} 1$ and $\mathrm{T} 42 \mathrm{x} 1$ configurations of CCSM3, respectively.

\section{Tropical sea surface salinity}

Mean SSS from T85x1 is shown in Fig. 1a, along with the differences from WOA/P (Fig. 1b). Of interest here are the four tropical regions enclosed by the thick contours at $\pm 1.5 \mathrm{psu}$. They are in the central South Pacific, northwestern Indian Ocean, eastern South Atlantic, and eastern Pacific south of Panama. These biases develop within a few years and only the latter is positive. Throughout the Tropics, the evaporation flux from the ocean in both LY and T85x1 is relatively uniform between 40 and $60 \mathrm{mg} \mathrm{m}^{-2} \mathrm{~s}^{-1}$. In contrast, the time-mean precipitation varies by an order of magnitude, from less than 10 to more than $100 \mathrm{mg} \mathrm{m}^{-2} \mathrm{~s}^{-1}$. Therefore, away from continental runoff, it sets the pattern of the net freshwater forcing. This range is evident in the mean T85x1 tropical precipitation, which is shown in Fig. 2 along with its difference from LY. The direct correspondence between these differences (Fig. 2b) and the
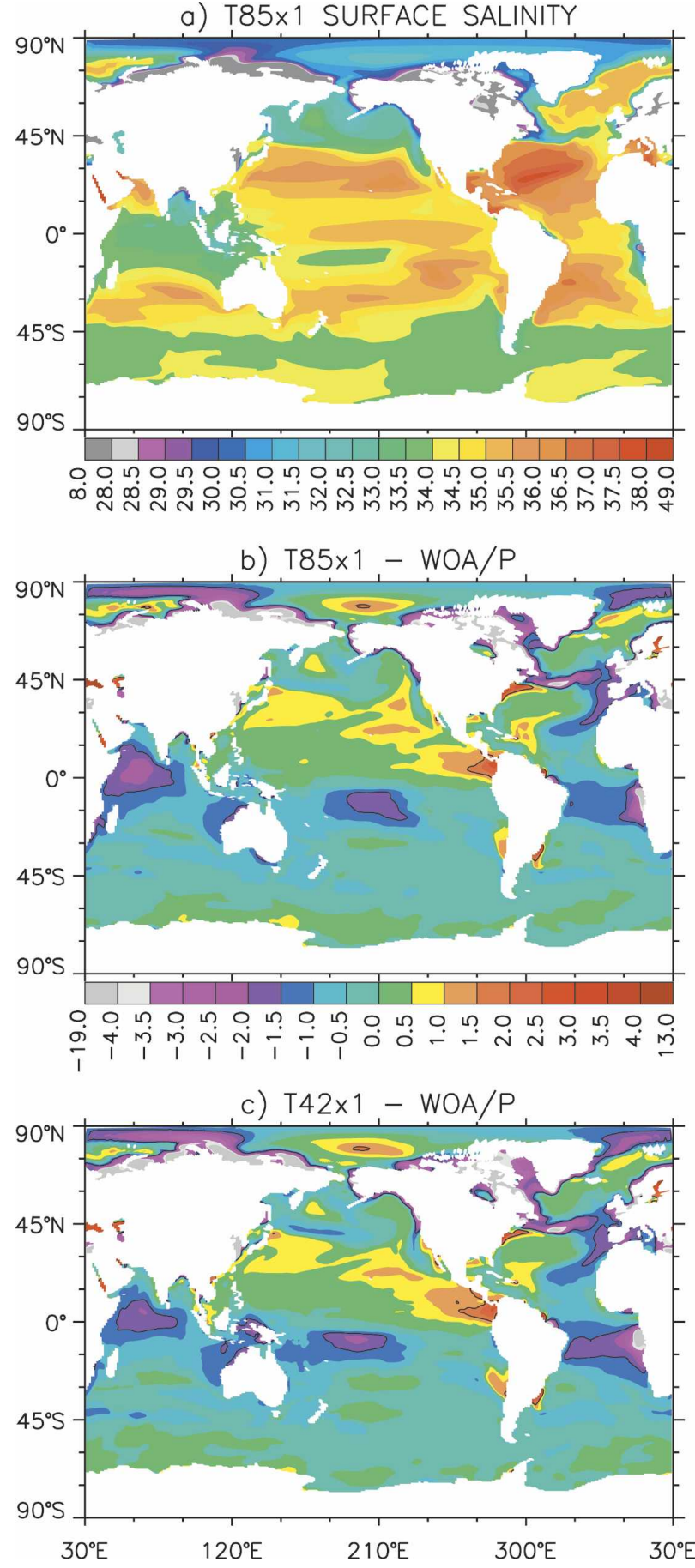

FIG. 1. Time-mean SSS (in psu): (a) from T85x1, (b) T85x1 WOA/P difference, and (c) T42x1 - WOA/P difference. The difference distributions have the same color scale, and $\pm 1.5 \mathrm{psu}$ contour lines are drawn.

biases in Fig. 1b, together with spatially uniform evaporation, suggest that the large tropical SSS biases are primarily attributable to errors in the precipitation from the atmosphere. Further support for this conclu- 


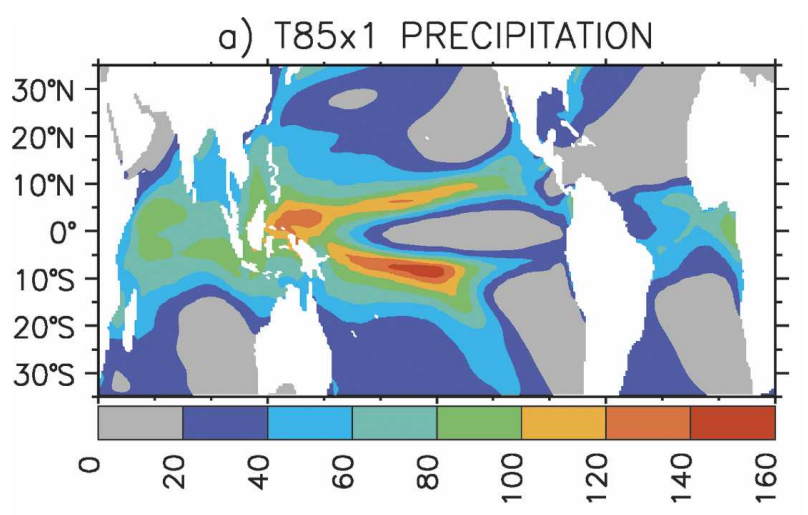

b) $T 85 \times 1-L Y$

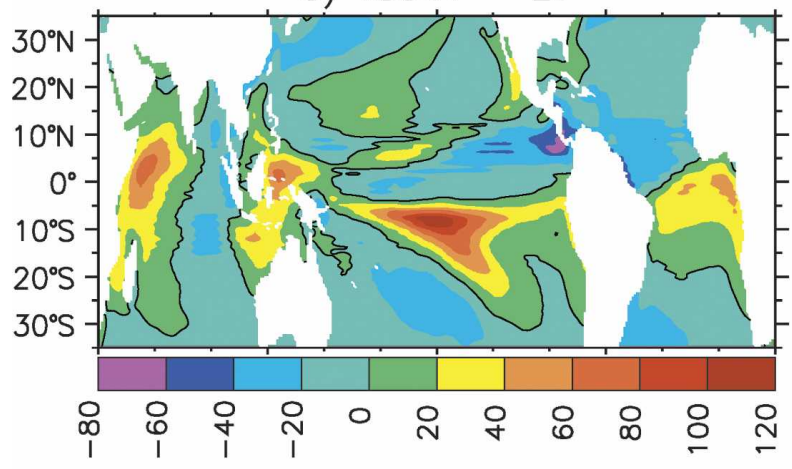

c) $T 42 \times 1-L Y$

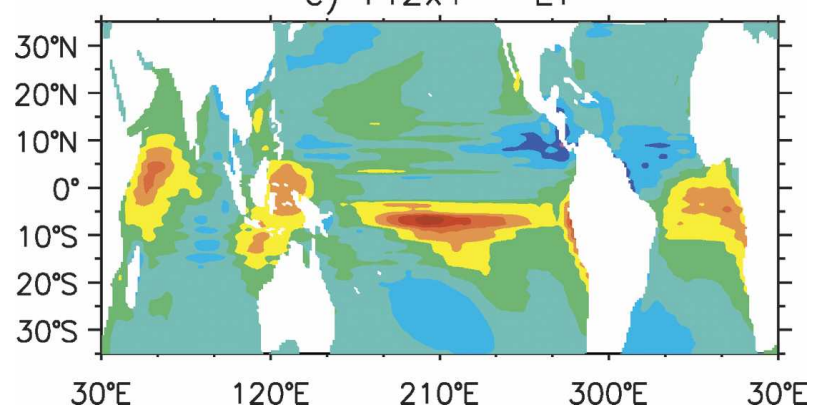

FIG. 2. Time-mean precipitation (in $\mathrm{mg} \mathrm{m}^{-2} \mathrm{~s}^{-1}$ ): (a) from T85x1, (b) T85x1 - LY difference, and (c) T42x1 - LY difference. The difference distributions have the same color scale and the zero contour line is drawn. All data are smoothened using five passes of a Laplacian filter.

sion emerges from the following examination of each region, where the biases over land and in T85cam are taken from Hack et al. (2006b). What causes the precipitation errors is beyond the scope of this study.

To utilize 100-yr integrations of T42x1 configurations for impact assessments in sections 5 and 6 , it is necessary to demonstrate that the long-term biases in $\mathrm{T} 85 \mathrm{x} 1$ are similar to those that develop in T42x1 in less than $100 \mathrm{yr}$. This is done for SSS and precipitation in Fig. 1c and Fig. 2c, respectively, where all the above major features of $\mathrm{T} 85 \mathrm{x} 1$ are clearly identifiable in the $\mathrm{T} 42 \mathrm{x} 1$ results from years $71-100$. Therefore, the conclusions and inferences concerning SSS and precipitation in T85x1 equally apply to T42x1.

A longstanding problem with many climate models of the atmosphere is the "double" intertropical convergence zone (ITCZ). Figure $2 b$ shows the manifestation of this problem in $\mathrm{T} 85 \mathrm{x} 1$ as a zonal band of excess precipitation across the southern equatorial Pacific at about $8^{\circ} \mathrm{S}$. The southward extension represents an eastward displacement of the rainfall associated with the South Pacific convergence zone. Most of this excess freshwater is transported south where it is lost through excess evaporation in the subtropics (Hack et al. 2006b). These error patterns of T85x1 rainfall and transport are consistent with the central Pacific SSS bias in Fig. 1b. Coupling appears to amplify the problem, because the double ITCZ precipitation is only about $30 \mathrm{mg} \mathrm{m}^{-2} \mathrm{~s}^{-1}$ greater than LY in T85cam, compared to $100 \mathrm{mg} \mathrm{m}^{-2} \mathrm{~s}^{-1}$ in Fig. 2b. Without compensating ocean salt transport, such precipitation is capable of rapidly reducing SSS. For example, a $50 \mathrm{mg} \mathrm{m}^{-2} \mathrm{~s}^{-1}$ excess in $F_{o}$ would decrease the salinity over the upper

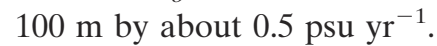

The fresh bias in SSS in the western tropical Indian Ocean also appears to be due mainly to excess local precipitation from the atmosphere, which is about 80 $\mathrm{mg} \mathrm{m} \mathrm{m}^{-2} \mathrm{~s}^{-1}$ in T85x1 (Fig. 2b) and $50 \mathrm{mg} \mathrm{m}^{-2} \mathrm{~s}^{-1}$ in T85cam. However, there may also be a small remote contribution from the excess precipitation that falls over central Africa, much of which is routed through rivers back to the coastal ocean, including the Indian Ocean coast of Africa. The role of African river runoff is more important in the South Atlantic, because in $\mathrm{T} 85 \mathrm{x} 1$ the Congo discharges more than double the observed freshwater. To quantify, the runoff from $10^{\circ} \mathrm{S}$ to the equator is $0.106 \mathrm{~Sv}$ compared to the LY estimate of $0.047 \mathrm{~Sv}$. The difference, if spread out evenly within $1000 \mathrm{~km}$ of the coast, is equivalent to $60 \mathrm{mg} \mathrm{m}^{-2} \mathrm{~s}^{-1}$ of rainfall, which is comparable to the precipitation bias in Fig. $2 \mathrm{~b}$ in its contribution to the very fresh SSS bias along the eastern margins of the South Atlantic in Fig. 1b. Equatorward and westward transport of this freshwater by ocean currents produces the large area of negative $\delta$ SSS all across the equatorial South Atlantic. Another indication of excess rainfall over central Africa is the order-of-magnitude-too-large Nile discharge, 0.030 versus $0.002 \mathrm{~Sv}$ (Perry et al. 1996), into a too fresh eastern Mediterranean Sea (Fig. 1a).

Lack of rainfall would appear to be a major cause of the positive $\delta$ SSS south of Panama because of the -60 $\mathrm{mg} \mathrm{m} \mathrm{m}^{-2} \mathrm{~s}^{-1}$ bias in Fig. 2b. T85cam tends to rain too much in this area, so coupled behavior of the ocean and atmosphere may be an issue, with the neighboring con- 


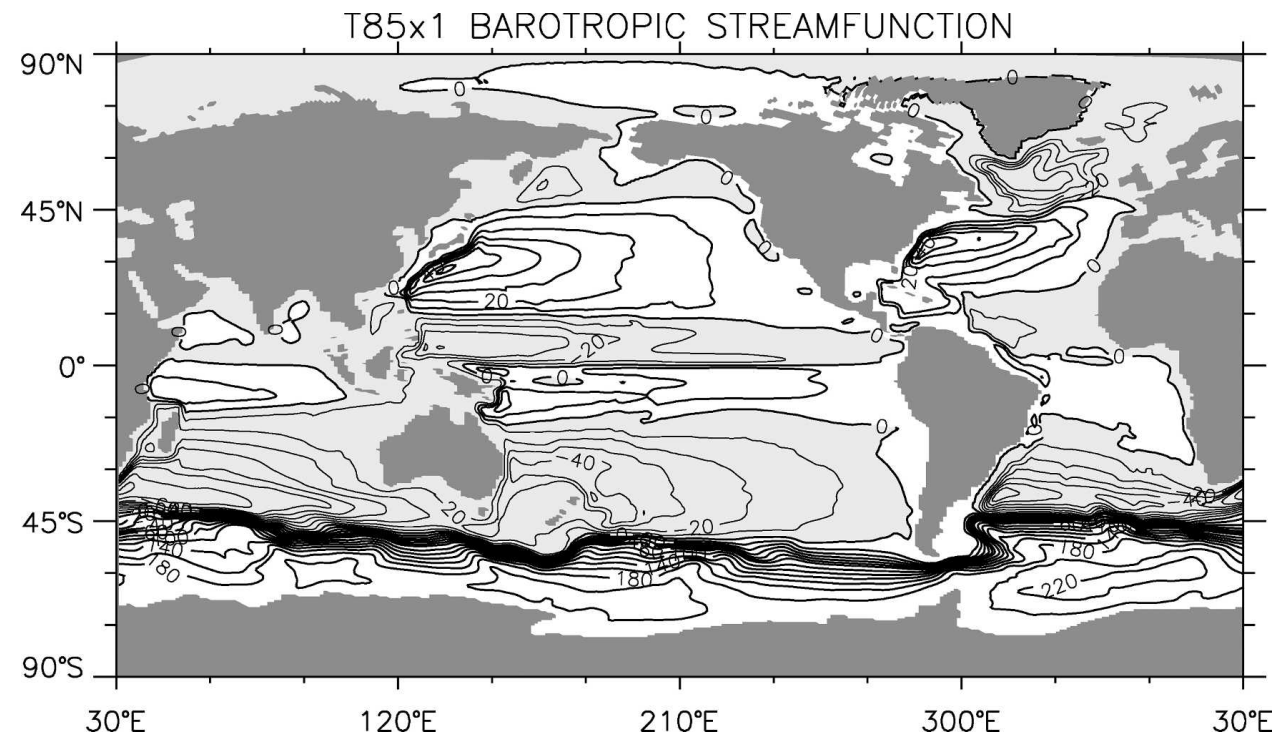

FIG. 3. Time-mean, vertically integrated mass transport (barotropic) streamfunction from T85x1. The contour intervals are 10 and $20 \mathrm{~Sv}$ for transports smaller and greater than $60 \mathrm{~Sv}$, respectively. The thick and thin (shaded regions) lines denote clockwise and counterclockwise circulations, respectively.

tinental orography a possible contributor through its effects on winds and clouds.

\section{Ocean circulation}

Atmospheric wind patterns, ocean bottom topography, and the earth's rotation combine to produce interbasin exchanges and the oceanic gyre circulation, with intensified western boundary currents (WBCs). In CCSM3 only the rotation is properly represented. The atmospheric model, and in particular its eddy momentum convergence aloft, largely determines the surface wind stress. The topography is smoothed to suppress numerical noise, and its intersection with the surface (land boundaries) must follow the coarse horizontal resolution and is altered to resolve narrow passages (e.g., Florida Strait, Gibralter Strait, and Indonesian Throughflow). The deep, buoyancy-driven circulation is discussed by Bryan et al. (2006) and Yeager et al. (2006).

A common model diagnostic representing the ocean circulation is the barotropic streamfunction, which is shown for T85x1 in Fig. 3. In the North Atlantic, the maximum transports of $50 \mathrm{~Sv}$ by the subtropical gyre, and over $40 \mathrm{~Sv}$ by the subpolar gyre, are comparable to the respective estimates of $48 \mathrm{~Sv}$ across $68^{\circ} \mathrm{W}$ by Johns et al. (1995) and $44 \mathrm{~Sv}$ by Pickart et al. (2002). The strength of the North Pacific subtropical gyre reaches over $60 \mathrm{~Sv}$ compared to the Qui and Joyce (1992) estimate of $52.4 \mathrm{~Sv}$ along $137^{\circ} \mathrm{E}$. A measure of the Indian subtropical gyre is the transport off the Cape of Good
Hope, which according to Gordon (2001) approaches $100 \mathrm{~Sv}$, but is only about $85 \mathrm{~Sv}$ in Fig. 3. The South Atlantic subtropical (SAST) gyre transport exceeds 60 Sv-about double that of $x 1$ locn and more than double observational estimates (Peterson and Stramma 1991).

Table 1 compares observed (section $2 \mathrm{~b}$ ) and modeled ocean volume transports through select passages. Of the interbasin exchanges, the model transports through Bering Strait and the ITF are in good agreement when measurement uncertainty and interannual variability are considered. However, the coupled Antarctic Circumpolar Current (ACC) is much too large in $\mathrm{T} 85 \times 1$ $(\mathrm{DPT}=192 \mathrm{~Sv})$, and only 10\% smaller in T42x1 (DPT $=176 \mathrm{~Sv})$. The inferred source of this bias is the coupled surface forcing, rather than ocean model physics because in x1ocn DPT $=143 \pm 3 \mathrm{~Sv}$ agrees within uncertainties with the observations (Table 1). Further-

TABLE 1. Comparison of ocean transport from x1ocn (19842000), T85x1 (years 571-600), and T42x1 (years 71-100) to the observational estimates quoted in section $2 \mathrm{~b}$. These volume transports in Sverdrups $\left(10^{6} \mathrm{~m}^{3} \mathrm{~s}^{-1}\right)$ are between Florida and Cuba (FCT), and through Drake Passage (DPT), the Indonesian Throughflow (ITF) and the Bering Strait (BST). They are given as mean \pm 1 standard deviation, or as a range to match the particular observation.

\begin{tabular}{lcccc}
\hline \hline & FCT & DPT & ITF & BST \\
\hline Observed & $25 \pm 1$ & $134 \pm 13$ & $10-15$ & $0.8 \pm .5$ \\
x1ocn & $29 \pm 1$ & $144 \pm 4$ & $12-16$ & $1.0 \pm .2$ \\
T85x1 & $28 \pm 1$ & $192 \pm 3$ & $12-16$ & $1.1 \pm .3$ \\
T42x1 & $28 \pm 1$ & $176 \pm 2$ & $13-19$ & $0.8 \pm .3$ \\
\hline
\end{tabular}


a) $T 85 \times 1$ WIND STRESS

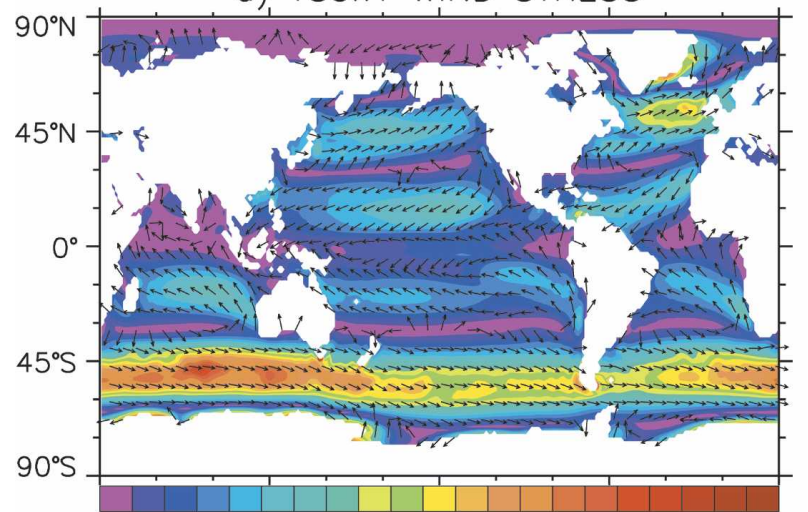

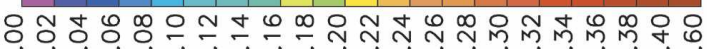

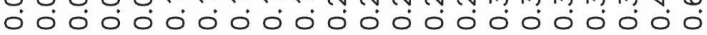

b) $T 85 \times 1-$ QSCAT

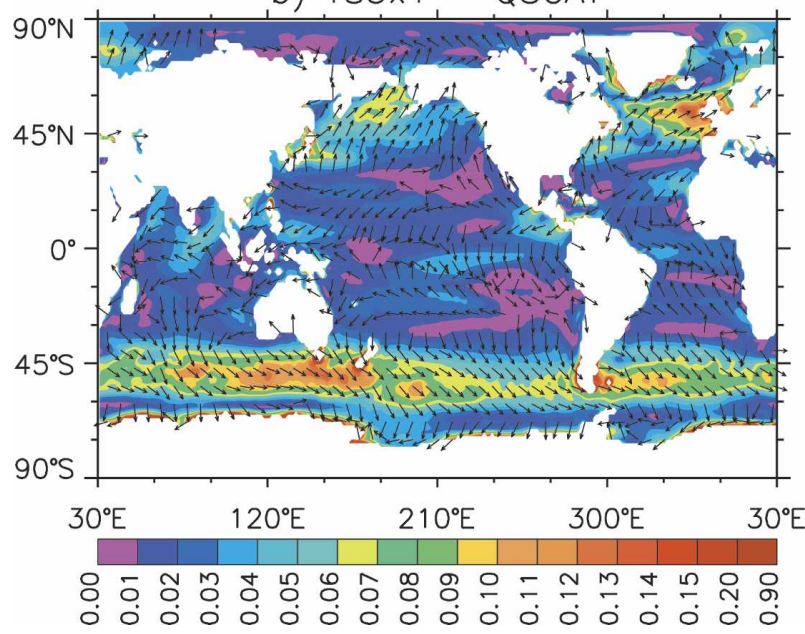

FIG. 4. Time-mean surface wind stress (in $\mathrm{N} \mathrm{m}^{-2}$ ) plotted on the atmospheric grid: (a) from T85x1 and (b) T85x1 - QSCAT difference. The color contours show the stress and difference magnitude distributions in (a) and (b), respectively. The arrows are drawn at every fifth grid point in each direction and are not to scale.

more, most of the error can be attributed to the too strong eastward wind stress at ACC latitudes.

The spatial distribution of this wind bias is quantified in Fig. 4. From $45^{\circ}$ to $60^{\circ} \mathrm{S}$ the time-mean stress in T85x1 exceeds QSCAT by $0.05 \mathrm{~N} \mathrm{~m}^{-2}$, or $\approx 35 \%$, in the less windy regions, and by more than $0.14 \mathrm{~N} \mathrm{~m}^{-2}$, or $\approx 50 \%$, where the winds are higher. These biases are much greater than can be attributed to the QSCAT measurements (section 2). They appear to be part of a general tendency for CCSM3 winds to be too strong throughout the extratropics, as indicated by difference vectors in Fig. 4b aligned with the stress direction in Fig. 4a. This bias is particularly evident in the zonal means of wind stress components shown in Yeager et al. (2006) for T85x1 as well as other coupled CCSM3 configurations. In particular, the mean zonal air-sea stress between $50^{\circ}$ and $55^{\circ} \mathrm{S}$ in $\mathrm{T} 85 \mathrm{x} 1$ is $0.8 \mathrm{~N} \mathrm{~m}^{-2}$, or $50 \%$, greater than QSCAT. The T42x1 winds are somewhat weaker than $\mathrm{T} 85 \mathrm{x} 1$ at these ACC latitudes, which is consistent with the difference in DPT.

Gent et al. (2001) find that in earlier versions of CCSM, the zonal wind stress drives a meridional Ekman transport, which in turn drives about $70 \%$ of the Drake Passage transport, with the thermohaline circulation responsible for the remainder. Therefore, the DPT bias in $\mathrm{T} 85 \mathrm{x} 1$ corresponds to about a $50 \%$ increase in the wind driving, or a doubling of the thermohaline contribution. The latter possibility is not supported by the nonuniform sign of SST, SSS, and heat flux biases at ACC latitudes in Figs. 5b, 1b, and 6b, respectively. However, the former is consistent with the magnitude of the wind stress error. Also, the vertical distribution of the T85x1 - x1ocn DPT difference suggests dominant wind driving. It is greatest at the surface and decays with depth such that more than half is found above $1000 \mathrm{~m}$.

In all the models the transport between Florida and Cuba must be the same as between Yucatan and Cuba and is about $10 \%-20 \%$ larger than observed (Table 1). In configuring the ocean model, transport through the Florida Strait was found to be sensitive to the bottom topography associated with the Bahamas. Standard smoothing tends to deepen the ridges, but by raising them back up in this region the transports increased by more than $10 \mathrm{~Sv}$ to give $\mathrm{FCT}=29 \mathrm{~Sv}$ in x1ocn (Table 1). There is little effect on the strength of the subtropical gyre, but the partition between FCT and flow on either side of the Bahamas is changed. Therefore, FCT in all models could be made to match the observations by modifying the topography, but such action could be just compensating for other problems.

The structure, separation, and pathways of western boundary currents and their extensions have always been difficult to achieve in ocean models, even at high resolution (Smith et al. 2000). In the first version of the present model, the Gulf Stream remained attached to the coast as far as Newfoundland (Danabasoglu 1998). With the addition of anisotropic viscosity it separates near Cape Hatteras in CCSM3 (Fig. 3), provided there is sufficient smoothing of the bottom topography (Doney et al. 2003). However, the combination of coarse resolution and high viscosity makes it far too wide, so at least one of its boundaries must be displaced. Doney et al. (2003) show that the northern edge is the better positioned at separation. With total transport fixed by the wind, the wide, surface-intensified current does not penetrate deep enough to feel an even 
a) T85x1 SURFACE TEMPERATURE

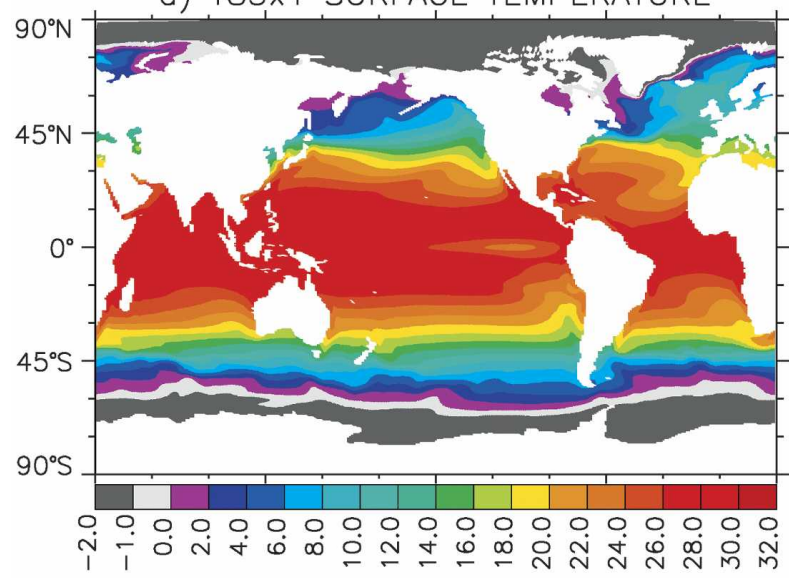

b) $T 85 \times 1-$ OBSERVED

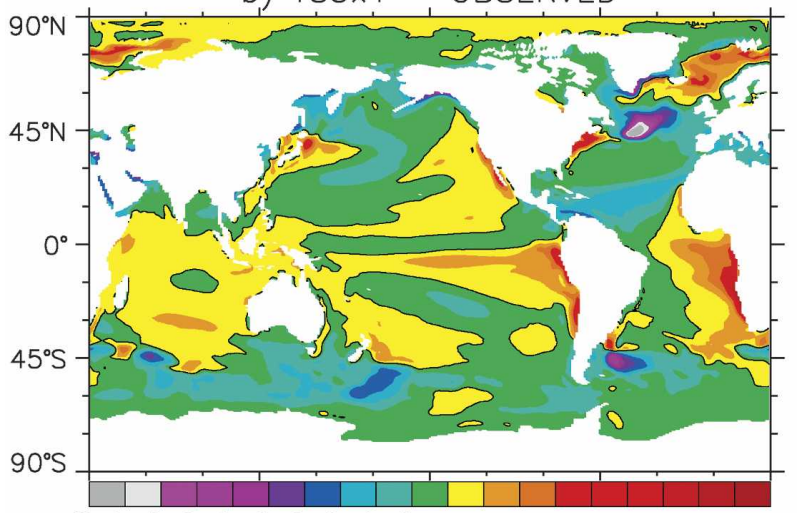

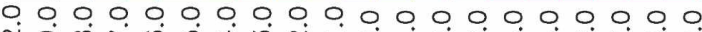

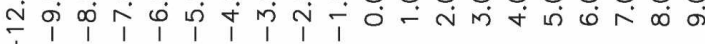

c) T42×1 - OBSERVED

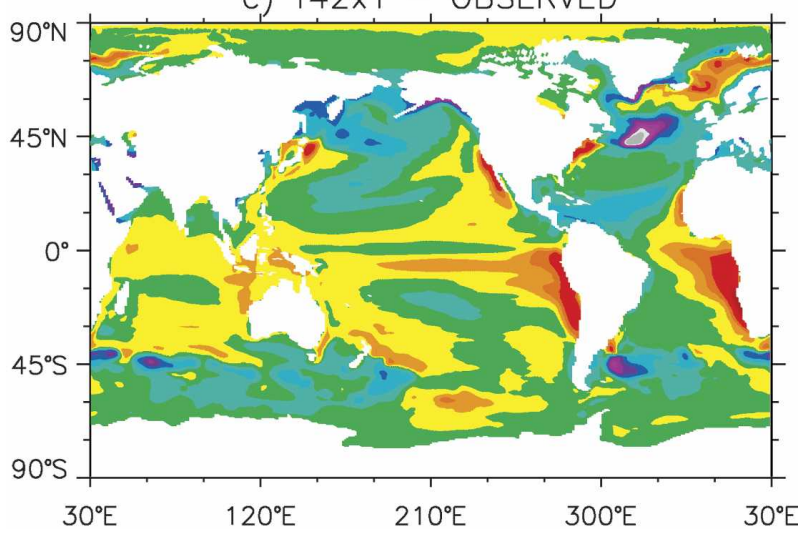

FIG. 5. Time-mean SST (in ${ }^{\circ} \mathrm{C}$ ): (a) from T85x1, (b) T85x1 difference from observations, and (c) T42x1 difference from observations. The difference distributions have the same color scale, and $0^{\circ} \mathrm{C}$ contour line is drawn.

unsmoothed ocean bottom properly. One apparent consequence is that the North Atlantic Current (NAC) fails to reconnect with the topography off the Grand Banks and instead remains too zonal. There is a north- ward excursion, but it is much farther east near the Mid-Atlantic Ridge (Fig. 3).

Biases quickly develop in the northwest Atlantic where subpolar surface water displaces the warm, salty water of the NAC. They become more than 4 psu too fresh (Fig. 1b) and $10^{\circ} \mathrm{C}$ too cold (Fig. 5b). The counteracting ocean heat flux bias of about $150 \mathrm{~W} \mathrm{~m}^{-2}$ (Fig. $6 \mathrm{~b}$ ) is only about half that predicted by (3), because about $50 \mathrm{~W} \mathrm{~m}^{-2}$ of the feedback is sensible heat flux that tends to cool the near-surface atmosphere. Reduced evaporation (less latent heat flux cooling) accounts for most of the remainder.

The Kiroshio is also far too wide, but with a reasonable separation (within the grid resolution) of its southern edge and positioning of its extension. The poleward displacement of the northern edge leads to a 1 psu saline bias in Fig. $1 \mathrm{~b}$ and $4^{\circ} \mathrm{C}$ warm bias in Fig. $5 \mathrm{~b}$ that are confined near the coast. Accordingly, the local model heat flux (Fig. 6) is about $100 \mathrm{~W} \mathrm{~m}^{-2}$ too negative (cooling).

Another strong WBC is the Agulhas, which loses its African coastline and flows westward around the Cape of Good Hope before retroflecting to the south and then recirculating eastward. The numerical study of Boudra and Chassignet (1988) shows that the process should not be well represented at the resolution and viscosities of the CCSM3 ocean. Therefore, it is not surprising that there is too little retroflection and that the $30 \mathrm{~Sv}$ of transport seen crossing the Atlantic to South America in Fig. 3 is too large. This flow is a major contributor to the SAST gyre transport biases in T85x1 and x1ocn.

Separation of the Brazil current is complicated by the Malvinas confluence where it meets the northward excursion of the ACC exiting Drake Passage. This region is not well represented in either T85x1 or $\mathrm{x} 1 \mathrm{ocn}$, and the SST and SSS biases are consistent with a northward and offshore displacement of the confluence. As a result, the offshore Antarctic water produces cold (Fig. 5b), fresh (Fig. 1b) biases, while next to the coast the subtropical Atlantic water is too warm and salty. In this region small systematic displacements lead to large SST biases because of strong horizontal gradients (Fig. 5). Similarly, the SST biases in the vicinity of the Agulhas retroflection represent rather small horizontal displacements of the SST field.

In summary, the major circulation biases in $\mathrm{T} 85 \mathrm{x} 1$ are the-much-too-strong ACC, the-more-than-a-factorof-2 greater than observed SAST gyre, and the poor WBC representation. Much of the latter is expected from the history of ocean modeling at the resolution of the CCSM3 ocean component. The modeled currents are overly viscous, too wide, and too shallow, but their 
a) T85x 1 SURFACE HEAT FLUX (SHF)

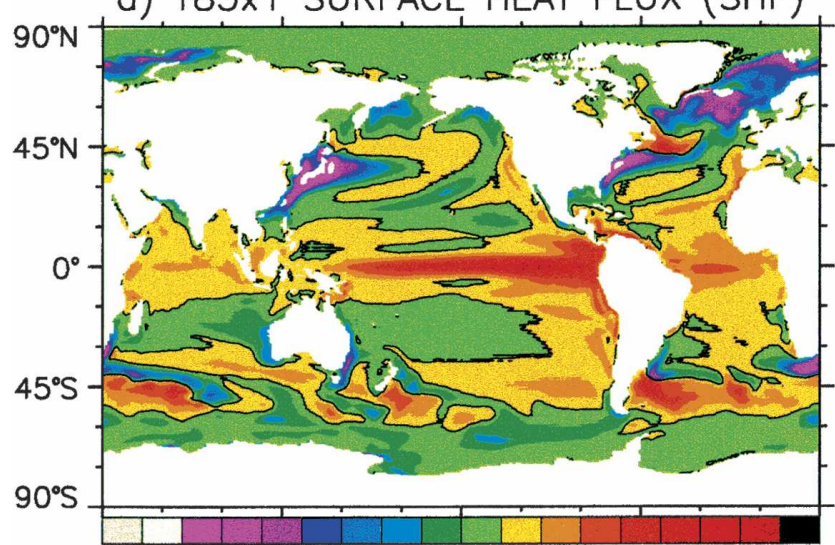

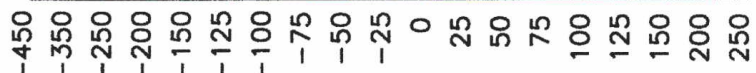

c) T85x1 SHORT-WAVE HEAT FLUX (SW)

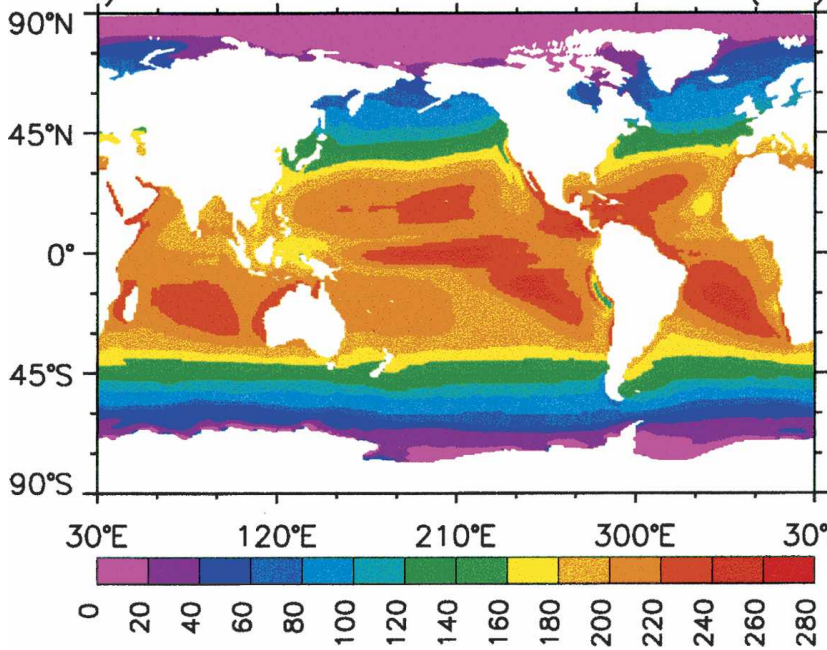

b) T85x1 SHF - LY

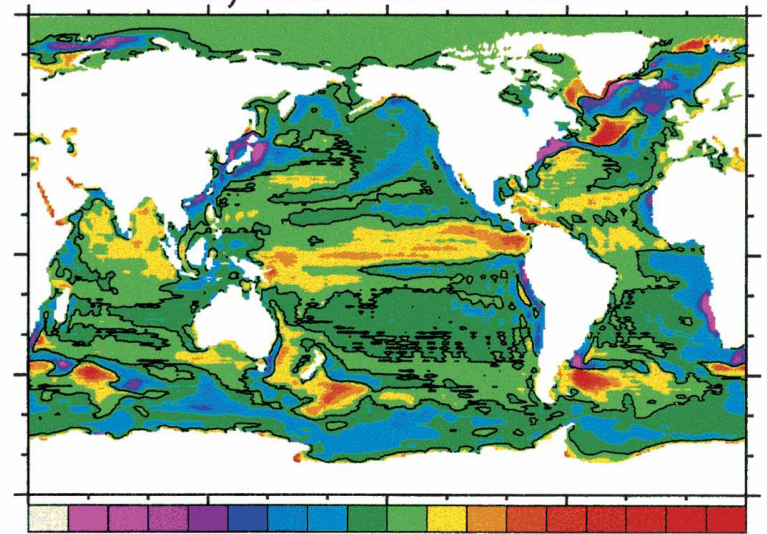

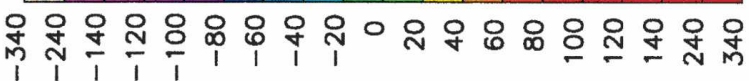

d) $T 85 \times 1 \mathrm{SW}-\mathrm{LY}$

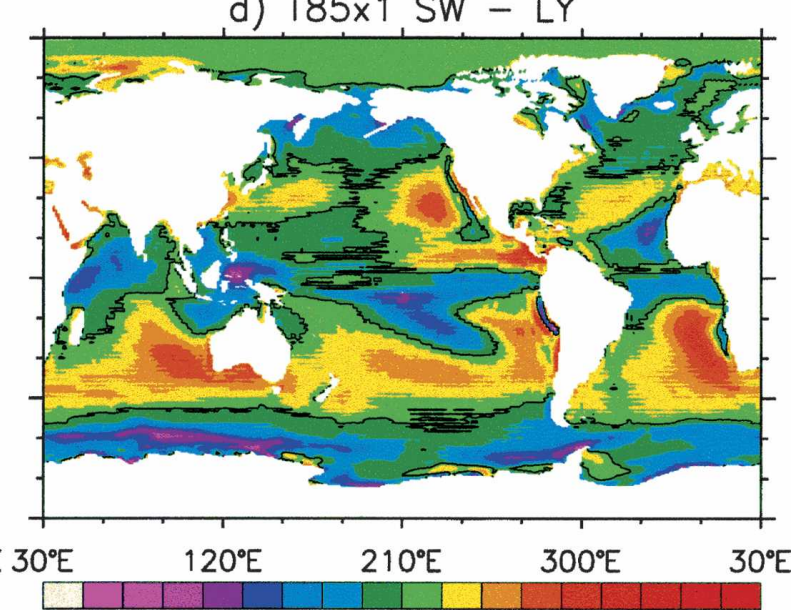

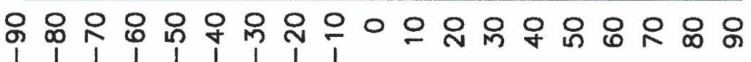

FIG. 6. Time-mean (a) surface total heat flux from T85x1, (b) its difference from LY, (c) net shortwave heat flux from T85x1, and (d) its difference from LY. The units are $\mathrm{W} \mathrm{m}^{-2}$, and $0 \mathrm{~W} \mathrm{~m}^{-2}$ contour line is drawn.

transport is generally set by the wind according to Sverdrup dynamics (Danabasoglu 1998). The too zonal path of the Gulf Stream leads to biases in SST and SSS that are larger in magnitude and spatial scale than those associated with the Kuroshio. In T85x1 less of the Agulhas retroflects than either observed or in x1ocn. Instead, $\approx 40 \mathrm{~Sv}$ traverses the South Atlantic and adds to the SAST gyre bias. The similarity of this behavior to the calculation of Godfrey (1989) suggests that Sverdrup dynamics are too dominant in this region of the model. The major SST and SSS biases associated with these two southern WBCs appear in the strong gradient regions downstream of the retroflection and near the Malvinas confluence. In contrast, the ACC bias appears mostly due to the overly strong zonal wind stress in the extratropics, but the effects on SST, SSS, and heat flux are not systematic. This wind bias may also contribute to the tendency for most wind-driven gyres to be somewhat stronger than observed, despite the model's viscosity.

\section{Ocean eastern boundaries}

The largest positive SST biases in Fig. 5 occur along the eastern boundaries of the subtropical ocean basins, most notably off the coasts of southwest Africa (SWA), Peru-Ecuador-Chile (PEC), and Baja-Southern California (BSC). The respective average biases within $15^{\circ}$ of these coasts are $3.2^{\circ}$ (equator to $30^{\circ} \mathrm{S}$ ), $1.7^{\circ}$ (equator to $\left.40^{\circ} \mathrm{S}\right)$, and $1.6^{\circ} \mathrm{C}\left(18^{\circ}\right.$ to $\left.38^{\circ} \mathrm{N}\right)$ for $\mathrm{T} 85 \times 1$, and $1.3^{\circ}$, $1.2^{\circ}$, and $0.7^{\circ} \mathrm{C}$ for $\mathrm{x} 1 \mathrm{ocn}$. Comparative numbers for other CCSM3 configurations are given by Yeager et al. 
(2006). Very large biases $\left(>4^{\circ} \mathrm{C}\right)$ extend for thousands of kilometers along these coasts but typically extend only about $300 \mathrm{~km}$ offshore. This section first presents evidence suggesting that a combination of problems with the atmosphere, ocean, and coupling are responsible for generating these warm temperatures, and associated salinity biases. The results of numerical experiments are then used to demonstrate the large-scale impacts of these biases on ocean temperature and salinity, and on atmospheric precipitation. A necessary condition for using 100-yr integrations of T42x1 for some of these experiments is the similarity in SST biases between T85x1 (Fig. 5b) and T42x1 (Fig. 5c).

These coastal regions have similar dynamics in both the ocean (weak eastern boundary currents and upwelling) and the atmosphere (stratus clouds and equatorward alongshore winds), so there may be common problems. In addition, the neighboring continents are mountainous. The Andes are the most extreme, but the coastal mountains of both California and Namibia do reach beyond $2000 \mathrm{~m}$. Such abrupt topography is not well represented in the spectral dynamics of the T85 atmosphere. Although spatial filtering minimizes the spectral ringing offshore and its undesirable consequence of the lower boundary extending below sea level, the penalty is that the bottom of the atmosphere remains above the ocean surface for a considerable distance offshore, with the unphysical gap often more than $1000 \mathrm{~m}$. Therefore, the meaning of the "near-surface" winds, temperature, and humidity used to compute airsea fluxes is ambiguous. Furthermore, near-coastal atmospheric grid boxes usually overlie both ocean and land, so the wind that drives the coastal ocean could be affected by the mountains represented within the land fraction of the grid box. The effect depends on local grid alignment and diminishes (increases) with increasing ocean (land) fraction and with topographic smoothness (roughness) of the land.

Quantitative evidence for the atmospheric model being at least partially responsible for the coastal SST biases is given by their sensitivity to atmospheric resolution (Yeager et al. 2006). Prime suspects are clouds and winds. In general, T85x1 winds are less upwelling favorable than QSCAT winds, as indicated by the poleward near-coastal wind stress differences in Fig. 4b. Only the southern SWA coast is more upwelling favorable (equatorward difference vectors). A lack of stratus clouds would allow too much radiative flux to reach the ocean. However, the net solar heating (Fig. 6c) differs from LY by at most about $50 \mathrm{~W} \mathrm{~m}^{-2}$ (Fig. 6d) - too little to increase SST by more than about $1^{\circ} \mathrm{C}$. Furthermore, the flux differences are not uniform either alongshore or offshore. In particular, just offshore in the
PEC region there is a negative bias equatorward of about $20^{\circ} \mathrm{S}$, and nearly equally strong positive biases farther south. Toward the equator and farther offshore, negative solar flux biases are highly correlated with excess precipitation (Fig. 2b) at all longitudes. A partial role for the atmosphere is also suggested by $\mathrm{T} 85 \mathrm{x} 1 \mathrm{ex}-$ periments that force the ocean with winds only from atmospheric cells entirely over the ocean. The bias pattern is similar to Fig. 5b, but the amplitude is reduced. In $x 1$ ocn the surface forcing is completely prescribed everywhere, and the biases are reduced further, especially along PEC, but remain significant.

Preliminary experiments were performed with the predecessor to CCSM3 (CCSM2) at T42x1 to quantify the effects of solar radiation and coastal winds on the eastern boundary SST biases. Similar experiments were not performed with CCSM3 because these biases are very similar in both magnitude and pattern (Kiehl and Gent 2004), despite the different model physics (Collins et al. 2006a) and atmospheric resolution. In one CCSM2 experiment both the net surface solar radiation and the surface wind stress ocean forcing were overridden by observed values only in the PEC region. Most of the SST bias was eliminated. Related experiments showed that individually both the radiation and wind each contributed about one-half of the reduction. A similar series of experiments off SWA and BSC reduced the biases by less than $40 \%$, with wind and radiation again equally effective.

The atmosphere has been shown to only partially explain the coastal biases, so the ocean may play a significant role, as suggested by the sensitivity to ocean resolution (Yeager et al. 2006). Coastal upwelling is known to bring cool water to the surface. It is driven by the surface Ekman divergence in response to the alongshore component of near-coastal winds. However, the strength and temperature are not known quantitatively, so it is unclear how well it is being represented in any model configuration.

In summary, the SWA, PEC, and BSC regions are characterized by the conjunction of several challenging modeling issues, which combine to produce large SST errors. Ocean upwelling plays an important role in the near-surface heat budget, but the process remains unresolved and has yet to be parameterized. In the atmosphere, both the winds that drive the upwelling and the surface radiation are suspect. The latter depends on the simulation of stratus clouds, which is not the best feature of atmospheric boundary layer schemes. The former may be particularly sensitive to any misalignment of the ocean and atmosphere grids. Also, there are numerical issues associated with the abrupt transi- 
tion from mountainous topography to a flat ocean that are particularly problematic in spectral models.

\section{Large-scale impacts}

A series of CCSM3 experiments was designed to determine the effect of the eastern boundary biases on the large-scale coupled model solutions. The methodology was simply to restore ocean temperature and salinity to WOA/P monthly values on a 10-day time scale, at all 19 vertical grid levels from the surface to $514 \mathrm{~m}$, everywhere within an eastern boundary region. The boundaries of the three regions are shown in Fig. 7. A control and several experiments with $\mathrm{T} 85 \mathrm{x} 1$ were spun up identically for $15 \mathrm{yr}$, and averages over the last $10 \mathrm{yr}$ (6-15) were analyzed and compared to the two 5-yr segments (6-10 and 11-15) to determine the robust signals. Restoring is applied to the regions both collectively (T85x1/ALL) and individually (T85x1/SWA, T85x1/ PEC and T85x1/BSC). Some potentially important signals in the equatorial Pacific differed significantly between the two 5-yr intervals because of ENSO variability. Resources were not available for longer $\mathrm{T} 85 \mathrm{x} 1$ experiments, so all three regions were restored in a T42x1 configuration (T42x1/ALL) for $100 \mathrm{yr}$. Comparisons of years $61-80$ and $81-100$ were used to confirm that the following results for the $30 \mathrm{yr}$ (71-100) are robust. As might be expected, the remote T85x1/ALL SST responses in the South Atlantic, South Pacific, and North Pacific are very similar to the signals found in T85x1/SWA, T85x1/PEC, and T85x1/BSC, respectively. Therefore, individual restoring was not repeated for T42x1.

Figure 7 shows the SST, SSS, and precipitation responses in the Tropics when temperature and salinity are restored in all three regions. These differences are T42x1 minus T42x1/ALL and have the same color contours as the biases in Fig. 5c, Fig. 1c, and Fig. 2c, respectively, so the more similar the figures, the more restoring has improved the biases. The precipitation is used as a measure of the atmospheric response to the combined changes in SST and wind induced by the restoring. The most extensive and robust responses are found in the South Atlantic, just as they are in T85x1/ ALL and T85x1/SWA (not shown). The inference is that without restoring, the much warmer and fresher waters that develop along SWA are advected by surface currents to the north and west, making most of the Atlantic between about $25^{\circ} \mathrm{S}$ and $5^{\circ} \mathrm{N}$ warmer, less saline, and hence less dense. The coupled response to these warmer SSTs includes subtle wind changes, presumably more local atmospheric convection, and too much rainfall (Fig. 7c). These effects combined with somewhat less evaporation from the sea surface ac-

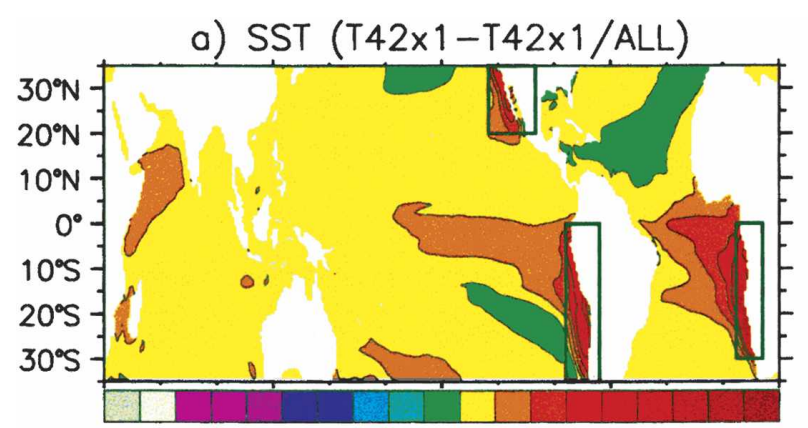

00000000000000000000

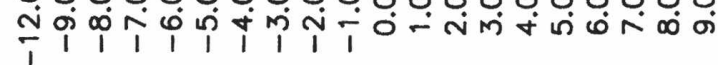

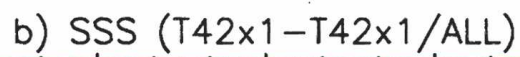

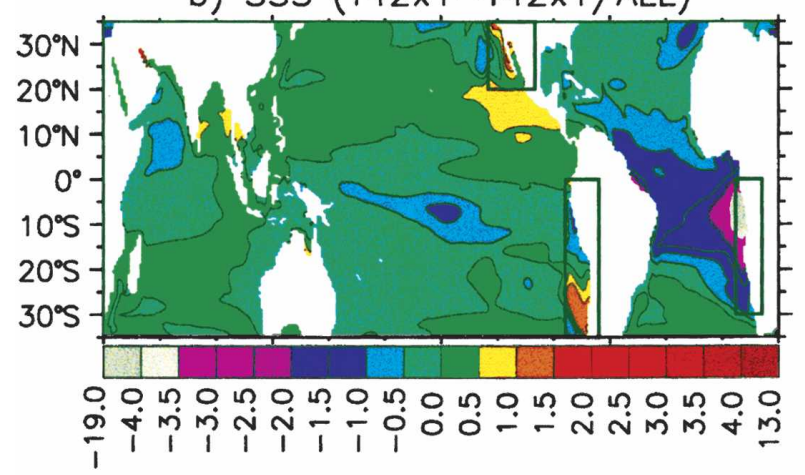

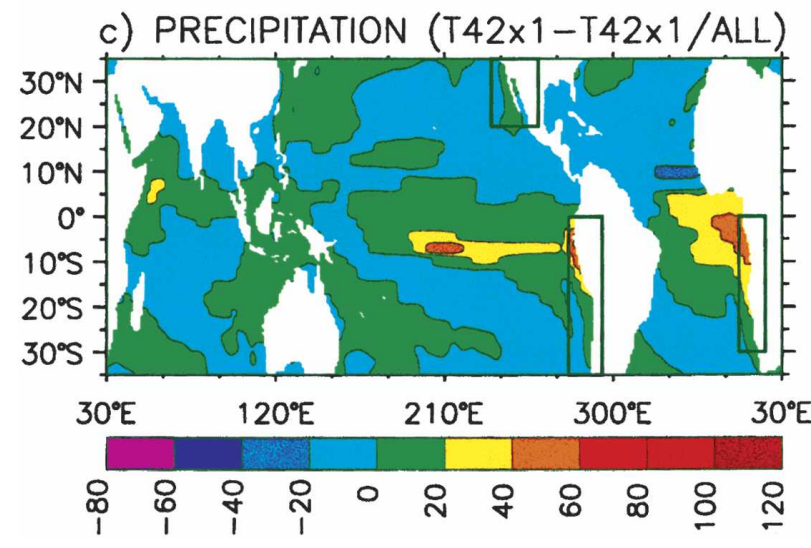

FIG. 7. Time-mean T42x1 - T42x1/ALL difference distributions for (a) surface temperature (in ${ }^{\circ} \mathrm{C}$ ), (b) surface salinity (in psu), and (c) precipitation (in $\mathrm{mg} \mathrm{m}^{-2} \mathrm{~s}^{-1}$ ). In (c), the precipitation data are smoothened using five passes of a Laplacian filter. The three boxed areas denote the eastern boundary restoring regions; SWA from $30^{\circ} \mathrm{S}$ to the equator and $7^{\circ}$ to $21^{\circ} \mathrm{E}, \mathrm{PEC}$ from $35^{\circ} \mathrm{S}$ to the equator and $276^{\circ}$ to $294^{\circ} \mathrm{E}$, and $\mathrm{BSC}$ from $20^{\circ}$ to $35^{\circ} \mathrm{N}$ and $235^{\circ}$ to $260^{\circ} \mathrm{E}$.

count for most of the greater-than-1-psu fresh biases of Fig. 1c. With restoring, the reduced precipitation to the south together with an increase along $10^{\circ} \mathrm{N}$ (Fig. 7c), leads to the formation of an Atlantic ITCZ concentrated along this latitude, where $70 \mathrm{mg} \mathrm{m}^{-2} \mathrm{~s}^{-1}$ mean precipitation off Africa agrees with LY. In the central 
Atlantic the rainfall is improved to within uncertainties (section $2 b$ ).

The large-scale remote precipitation responses are quantified in Table 2, as the change in the 10-yr (6-15) mean rainfall from the $\mathrm{T} 85 \mathrm{x} 1$ control averaged over the five regions defined in Table 2. In the tropical South Pacific there is significant cancellation of the PEC signal by the SWA. The essentially linear nature of this and other responses is demonstrated by the less than 1.8 $\mathrm{mg} \mathrm{m}^{-2} \mathrm{~s}^{-1}$ difference between the T85x1/ALL values and the sum of the three individual responses. The difference exceeds $15 \%$ only in the northwest Indian Ocean.

The pattern of precipitation along the SWA coast in T42x1/ALL is improved (by as much as $60 \mathrm{mg} \mathrm{m}^{-2} \mathrm{~s}^{-1}$ ) over Fig. 2c, presumably because of the restoring to colder temperatures. Therefore, removal of the fresh bias in Fig. 1 may not require salinity restoring, especially if the excess river runoff can be reduced. There is less runoff in this region in T42x1/ALL, but it is still about twice the LY estimate. SWA restoring also produces a robust, remote improvement in northwest Indian Ocean precipitation. Over the whole northwest Indian region the mean decreases from 71 to $66 \mathrm{mg} \mathrm{m}^{-2} \mathrm{~s}^{-1}$, but the greater-than-2-psu local salinity bias (Fig. 2c) is improved by only 0.5 psu (Fig. 7b).

There is little effect on North Pacific SST outside the restoring region either in Fig. $7 \mathrm{a}$ or T85x1/BSC (not shown). In the eastern equatorial South Pacific the advection of colder surface water does improve the SST in T42x1/ALL, except along the equator. The most significant and unexpected temperature signals in the $\mathrm{Pa}$ cific are found between 100- and 200-m depth. These are mostly captured in Fig. 8, where the biases in temperature at $130-\mathrm{m}$ depth in $\mathrm{T} 85 \mathrm{x} 1$ and $\mathrm{T} 42 \mathrm{x} 1$ are shown above the T42x1/ALL response. As with surface properties all the significant biases of $\mathrm{T} 85 \times 1$ are present in

TABLE 2. Differences from the T85x1 control in the 10-yr (6-15) mean rainfall $\left(\mathrm{mg} \mathrm{m}^{-2} \mathrm{~s}^{-1}\right)$ averaged over five regions, for four restoring experiments and the sum of the differences from the three individual restoring experiments. The regions are the Equatorial Atlantic (EQA) from $10^{\circ} \mathrm{S}$ to $5^{\circ} \mathrm{N}$, the tropical North Atlantic (TNA) from $10^{\circ}$ to $15^{\circ} \mathrm{N}$, the North West Indian (NWI) from the equator to $10^{\circ} \mathrm{N}$ and $50^{\circ}$ to $70^{\circ} \mathrm{E}$, the Tropical South Pacific (TSP) from $15^{\circ}$ to $5^{\circ} \mathrm{S}$ and $200^{\circ}$ to $290^{\circ} \mathrm{E}$, and the Tropical North Pacific (TNP) from the equator to $15^{\circ} \mathrm{N}$.

\begin{tabular}{lrrrrr}
\hline \hline & EQA & TNA & NWI & TSP & TNP \\
\hline T85x1/SWA & -54.1 & 6.5 & -5.0 & 3.6 & 3.3 \\
T85x1/PEC & 2.6 & 1.4 & 0.9 & -8.8 & 0.6 \\
T85x1/BSC & 1.5 & -0.5 & 0.9 & 0.7 & -0.1 \\
T85x1/ALL & -51.8 & 8.6 & -4.9 & -4.0 & 3.2 \\
SWA+PEC+BSC & -50.0 & 7.4 & -3.1 & -4.6 & 3.9 \\
\hline
\end{tabular}
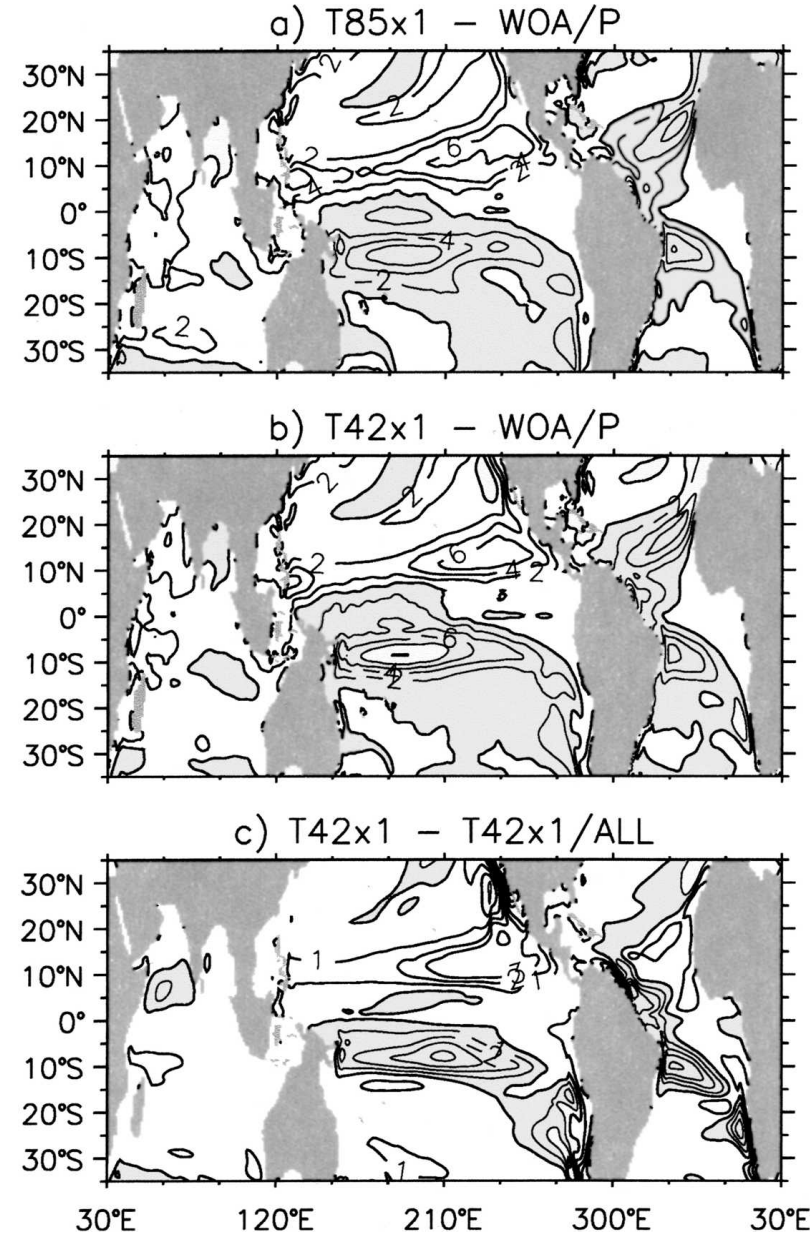

FIG. 8. Time-mean potential temperature difference distributions at 130-m depth for (a) T85x1 - WOA/P difference, (b) T42x1 - WOA/P difference, and (c) T42x1 - T42x1/ALL difference. The contour intervals are $2^{\circ} \mathrm{C}$ in (a) and (b) and $1^{\circ} \mathrm{C}$ in (c). The negative differences (thin lines) are shaded in all panels.

T42x1, where they are essentially fully developed within $100 \mathrm{yr}$. The $6^{\circ} \mathrm{C}$ bias in $\mathrm{T} 42 \mathrm{x} 1$ at $10^{\circ} \mathrm{N}$ is reduced by more than a half, even though there is no BSC restoring south of $20^{\circ} \mathrm{N}$. The colder waters appear to originate off Central America. In contrast, the signal in the western and central Pacific along about $7^{\circ} \mathrm{S}$ is much farther from the eastern boundary and represents a warming, which reduces the $\mathrm{T} 42 \mathrm{x} 1$ bias from $10^{\circ} \mathrm{C}$ to less than $5^{\circ} \mathrm{C}$. Similarly, in the western tropical Atlantic there is a large area, far removed from any restoring, where the $130-\mathrm{m}$ cold bias in T42x1/ALL is less than half the $\mathrm{T} 42 \mathrm{x} 1$ value.

Figure 9 shows that in the same remote region of the western Atlantic, the fresh salinity bias at $130 \mathrm{~m}$ of $\mathrm{T} 42 \times 1$ is almost entirely eliminated in T42x1/ALL. In the south Pacific the order -0.4 psu response suggests that about half the $\mathrm{T} 42 \mathrm{x} 1$ fresh bias is related to the 

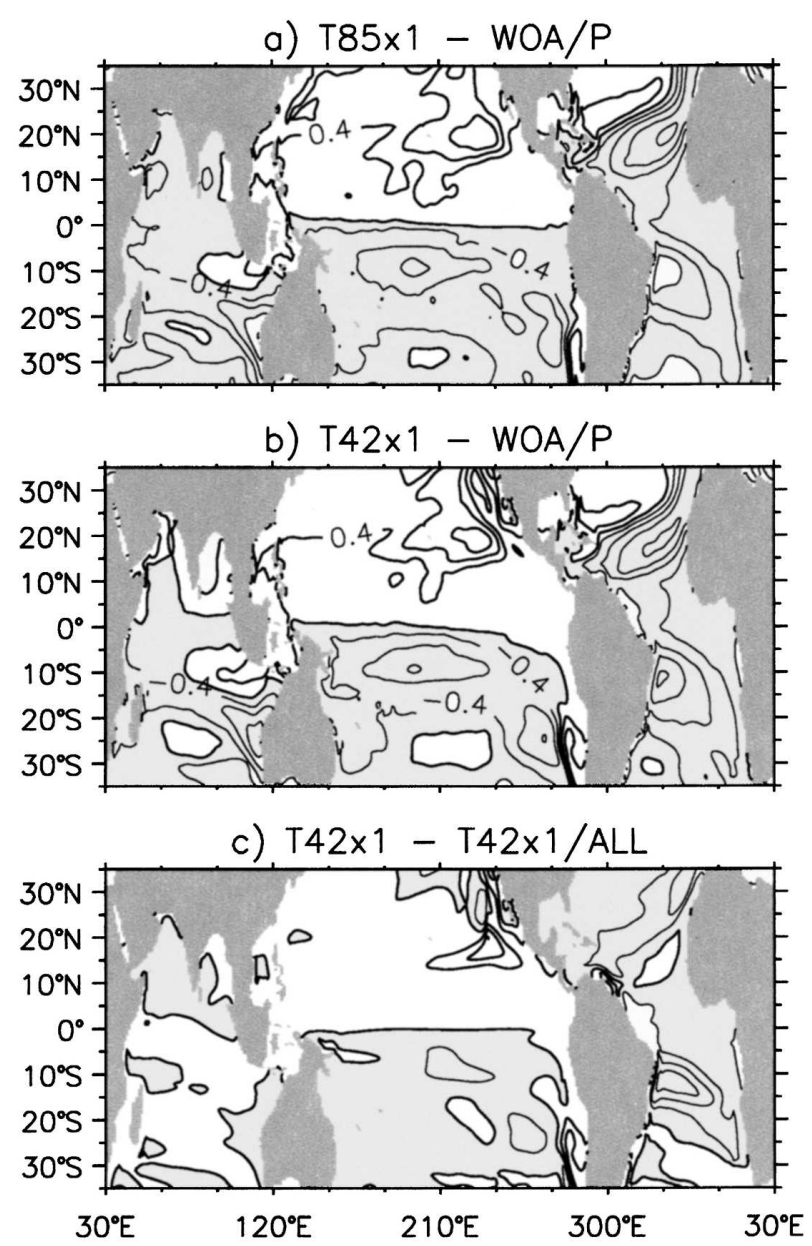

FIG. 9. Time-mean salinity difference at 130-m depth for (a) T85x1 - WOA/P difference, (b) T42x1 - WOA/P difference, and (c) T42x1 - T42x1/ALL difference. In all panels, the contour interval is $0.4 \mathrm{psu}$, and the negative differences (thin lines) are shaded.

eastern boundary problems. In general, a similar inference holds for the North Pacific too, especially south of about $20^{\circ} \mathrm{N}$. There are no significant remote signals in Indian Ocean salinity at 30-m depth.

The above eastern boundary biases are potentially very important to coupled model behavior because their effects are not locally confined. In addition to the apparent advection by surface currents, subsurface ocean pathways are suggested by signals that are seen at depth all across the Atlantic and Pacific Oceans. Atmospheric teleconnections are implicated by the precipitation signals in Fig. 7c, especially the diminution across $10^{\circ} \mathrm{N}$ in the Atlantic, some of the excess over central Africa, and the northwest Indian Ocean and the contribution to the double ITCZ. Related to the latter is the implication that $\mathrm{T} 85 \mathrm{x} 1$ precipitation errors in the tropical South Pacific region would have been worse without the SWA biases (Table 2).

\section{The equatorial Pacific Ocean}

An evaluation of equatorial Pacific biases in T85x1 is complicated by the very large interannual ENSO variability. This signal is of great interest and importance because of its global consequences. The excitement from an ocean perspective is that interannual changes in SST in the eastern equatorial Pacific are negatively correlated with the surface heating (Doney et al. 2003). Thus, ocean processes are not only driving the ENSO signals, but also overcoming the tendency for surface flux anomalies to dampen them according to (3). ENSO variability in CCSM3 is the subject of Deser et al. (2006) and is also considered in Danabasoglu et al. (2006) and Yeager et al. (2006). Here we examine the mean and seasonal cycle of the equatorial Pacific, on which the ENSO signals develop. The focus will be on the temperature, salinity, and zonal currents, as well as the seasonal cycle of the wind. Also of interest are the responses to restoring temperature and salinity in the PEC and BSC regions. It is important to consider the subsurface temperature because of the dominant role of ocean processes in the interannual heat budget. Attribution and impact assessment will primarily utilize comparisons of fully coupled $\mathrm{T} 85 \mathrm{x} 1$ with forced $\mathrm{x} 1 \mathrm{con}$ and T85cam, and of T42x1 with T42x1/ALL, respectively.

\section{a. Mean structure}

Mean zonal currents along the equatorial Pacific in $\mathrm{x} 1 \mathrm{ocn}, \mathrm{T} 85 \mathrm{x} 1, \mathrm{~T} 42 \mathrm{x} 1$, and T42x1/ALL are compared to observations in Fig. 10, where the depth of the Equatorial Undercurrent (EUC) core (maximum eastward zonal velocity) from the observations is shown as a dotted reference line in all panels. Most features are well represented in the coupled model solutions, including the westward surface flow, and the depth and strength of the EUC, though both T42x1 configurations are about $20 \%$ too weak. A prominent coupled model defect is the upper-ocean shear in the west. A major factor in its existence is the lack of sufficient coupled variability to produce the observed westerly wind bursts. Large et al. (2001) find that in a forced model like x1ocn, these events produce realistic ocean responses, including westward currents on the equator down to nearly $100 \mathrm{~m}$. At $147^{\circ} \mathrm{E}$, two events combine to reverse the surface current for almost half the year beginning in August 1996, in both observations and a model simulation, so they are a major factor in the mean current structure. The net effect in this vicinity is the absence of mean shear over the upper $100 \mathrm{~m}$ in both observations (Fig. 10a) and x1ocn (Fig. 10b). Another signature evident in these two figures is the eastward surface current 

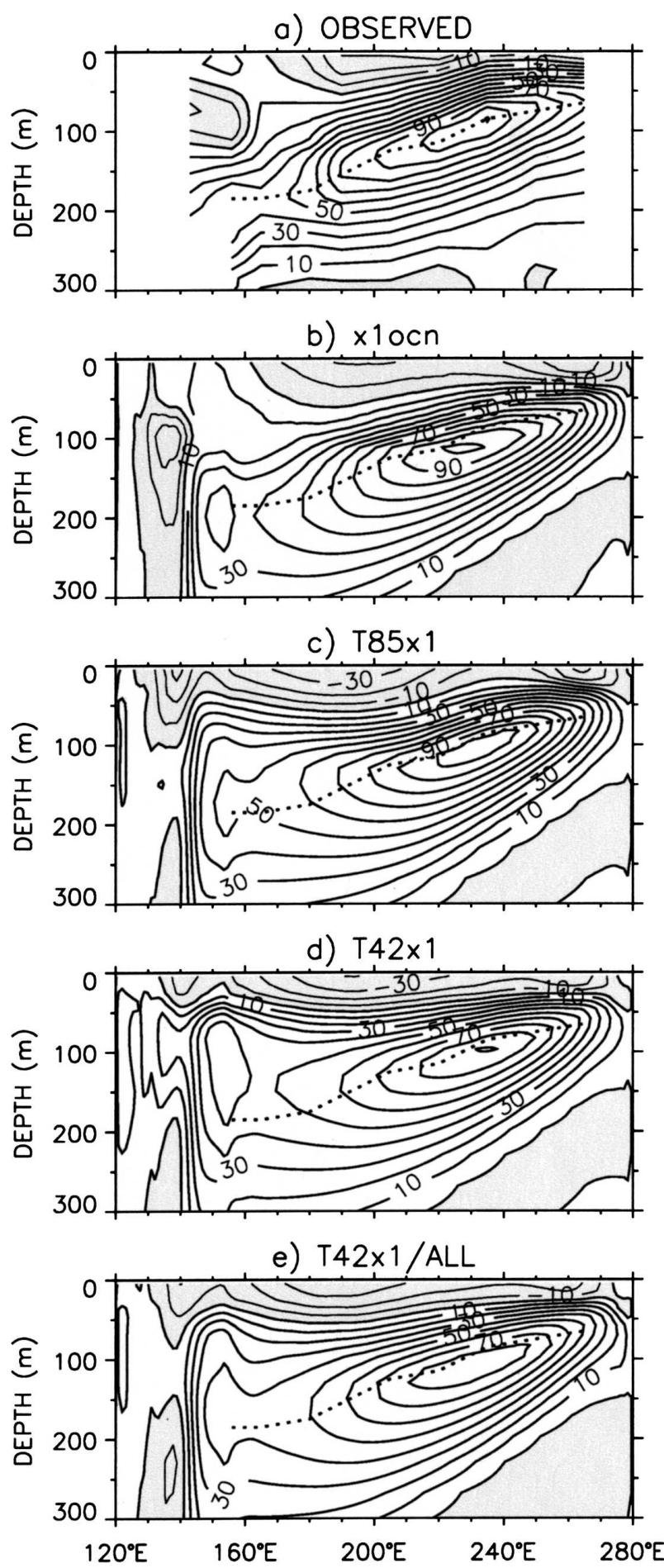

FIG. 10. Time-mean, equatorial Pacific zonal velocity from (a) observations (Johnson et al. 2002), (b) x1ocn (2000-2004), (c) T85x1, (d) T42x1, and (e) T42x1/ALL. The contour interval is 10 $\mathrm{cm} \mathrm{s}^{-1}$, and westward flow regions (thin lines) are shaded. The depth of the maximum eastward velocity from observations is shown by the dotted trace in all panels. everywhere west of about $160^{\circ} \mathrm{E}$, whereas coupled solutions display more westward surface flow.

Large biases in zonal currents develop off the equator in both coupled and uncoupled model solutions, as shown in Fig. 11. The westward (shaded) South Equatorial Current (SEC) between $\approx 10^{\circ} \mathrm{S}$ and $5^{\circ} \mathrm{N}$, and the eastward North Equatorial Counter Current (NECC) to the north both tend to be too weak in x1ocn. Sensitivity experiments indicate that a reduction in the minimum lateral viscosity (section 2c) from 1000 to about $500 \mathrm{~m}^{2} \mathrm{~s}^{-1}$ is sufficient to approach the observed NECC strength of $40 \mathrm{~cm} \mathrm{~s}^{-1}$. However, the numerical consequences have yet to be assessed.

In Fig. 11, the meridional sections from $\mathrm{T} 42 \mathrm{x} 1$ and $\mathrm{T} 85 \times 1$ are compared to the $\mathrm{x} 1 \mathrm{ocn}$ to support the case that the more symmetric wind and precipitation forcing in the coupled models are problematic. The x1ocn and observations show a distinct asymmetry, with the SEC stronger north of the equator, and a surface maximum in the NECC around $7^{\circ} \mathrm{N}$, with no corresponding South Equatorial Countercurrent (SECC). In contrast, the SEC in T85x 1 is stronger south of the equator, and a weak SECC appears at $7^{\circ} \mathrm{S}$ in both $\mathrm{T} 42 \mathrm{x} 1$ and $\mathrm{T} 85 \mathrm{x} 1$ to mirror a very weak NECC. The countercurrent biases in T42x1 appear to be partly linked to the forcing and ocean density errors associated with the eastern boundary biases, because in T42x1/ALL (Fig. 11e) there is no SECC and the NECC has doubled in strength.

The temperatures from WOA/P and model differences along the equatorial Pacific are shown in Fig. 12. The positive differences in both $\mathrm{x} 1 \mathrm{locn}$ and $\mathrm{T} 85 \mathrm{x} 1$ are more than expected from the equatorial problems with WOA/P, and hence suggest a ocean model problem. The warm bias at $200-\mathrm{m}$ depth at 180 , rising to $100 \mathrm{~m}$ farther east, is indicative of reduced temperature gradients around the core of the model EUC, where vertical mixing is governed by the background diffusivity. At these depths its coefficient is $0.1 \mathrm{~cm}^{2} \mathrm{~s}^{-1}$, but according to Gregg et al. (2003), this should be an order of magnitude smaller, but then numerical diffusion may become more involved. Shear instability mixing would not seem to be an issue here because of the large values of local Richardson number, Ri, found in the low-shear, high-stratification environment around the EUC core. The large biases in the far west of both T85x 1 and x1ocn may arise because of grid issues associated with New Guinea and other islands.

The large $\mathrm{T} 85 \mathrm{x} 1\left(-2.5^{\circ} \mathrm{C}\right)$ temperature bias at $130 \mathrm{~m}$ near the date line is not seen in x1ocn, so ocean atmosphere coupling could be a factor. Between 50 and 100 $\mathrm{m}$ the increasing negative difference with depth says the temperature gradient is too strong, which suggests that boundary layer mixing is not penetrating deep enough 

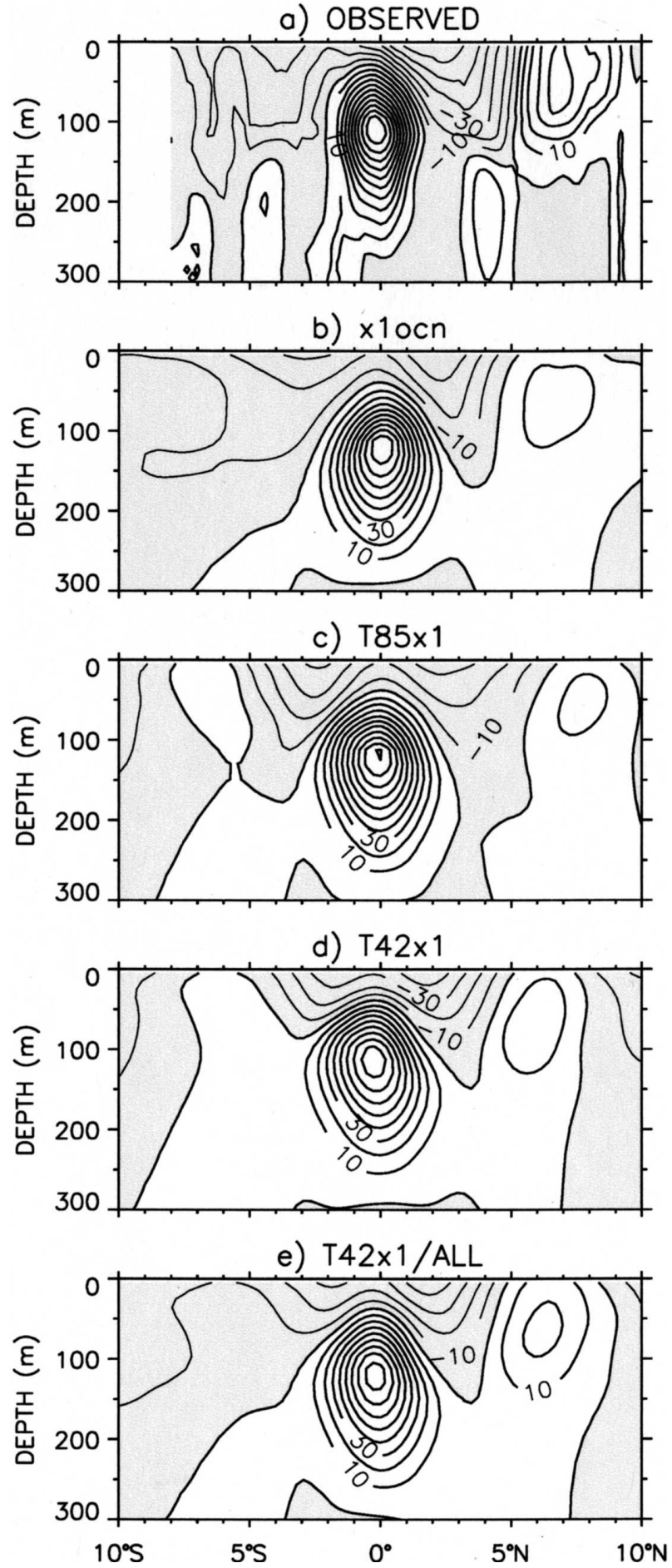

FIG. 11. Time-mean zonal velocity at $140^{\circ} \mathrm{W}$ in the Pacific Ocean from (a) observations (Johnson et al. 2002), (b) x1ocn (2000-04), (c) T85x1, (d) T42x1, and (e) T42x1/ALL. The contour interval is $10 \mathrm{~cm} \mathrm{~s}^{-1}$, and westward flow regions (thin lines) are shaded.
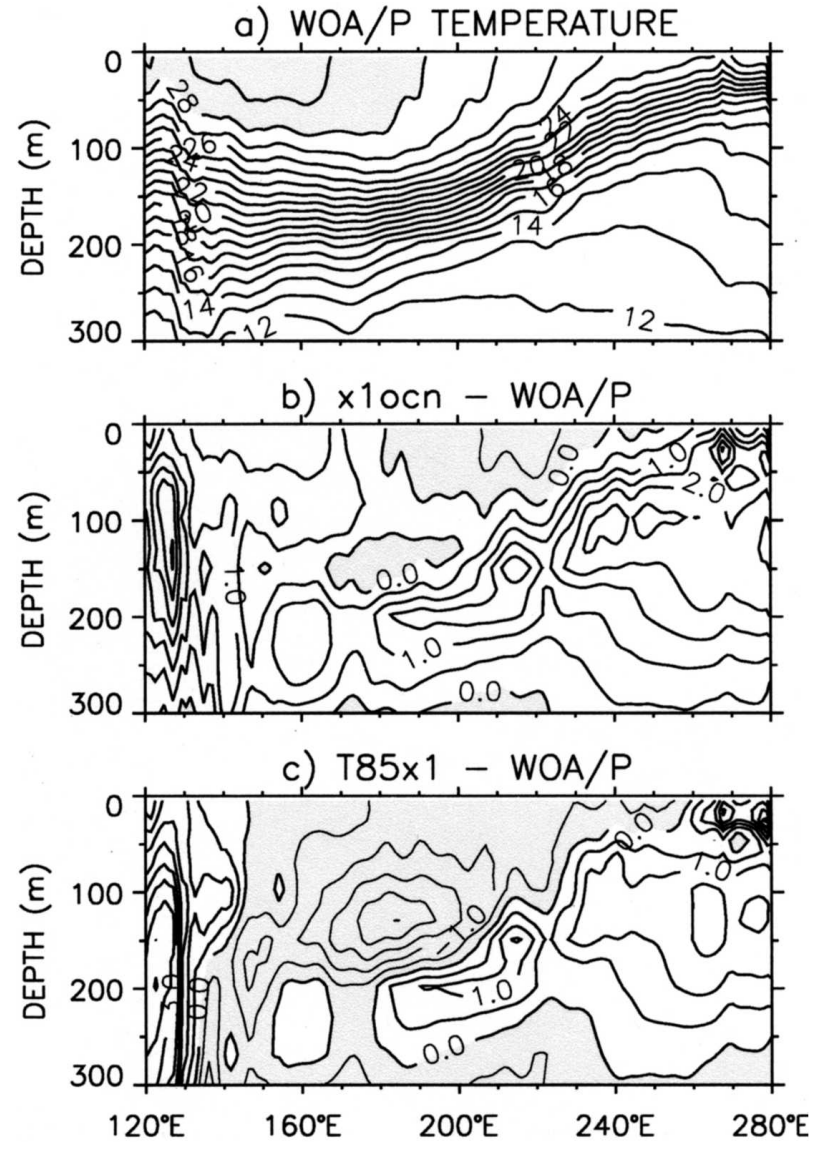

FIg. 12. Time-mean equatorial Pacific $\left(2^{\circ} \mathrm{S}-2^{\circ} \mathrm{N}\right.$ mean $)$ potential temperature (a) from WOA/P, (b) x1ocn (2000-04) - WOA/P difference, and (c) T85x1 - WOA/P difference. In (a), the contour interval is $1^{\circ} \mathrm{C}$ and the contours greater than $28^{\circ} \mathrm{C}$ are shaded. In (b) and (c), the contour interval is $0.5^{\circ} \mathrm{C}$ and the negative differences (thin lines) are shaded.

in the coupled model. Indeed, diagnosed mixed layer depths are less in T85x1 than x1ocn. Surface buoyancy flux is the most likely surface driving that could be responsible because the winds are not obviously too weak in Fig. 4. Figure $6 \mathrm{~b}$ shows about $60 \mathrm{~W} \mathrm{~m}^{-2}$ excess surface heating of the ocean in this region, which may be enough to suppress the boundary layer mixing, even though the excess upper-ocean shear in T85x1 (Fig. 10c) would tend to enhance it. The heating would seem to be in response to the cold SST following (3) because the solar bias in Fig. 6d is small. Also, the EUC in this region of T85x1 (Fig. 10c) is shallow, so advective processes in the model may be playing a role in generating this cold bias.

To explore $\mathrm{T} 85 \mathrm{x} 1$ further, consider the equatorial SST, which from Fig. $12 \mathrm{c}$ is too warm by up to $1.5^{\circ} \mathrm{C}$ in the far east and about $0.5^{\circ} \mathrm{C}$ in the extreme west, but $\approx 1^{\circ} \mathrm{C}$ too cold in the central Pacific. Tolerating this 

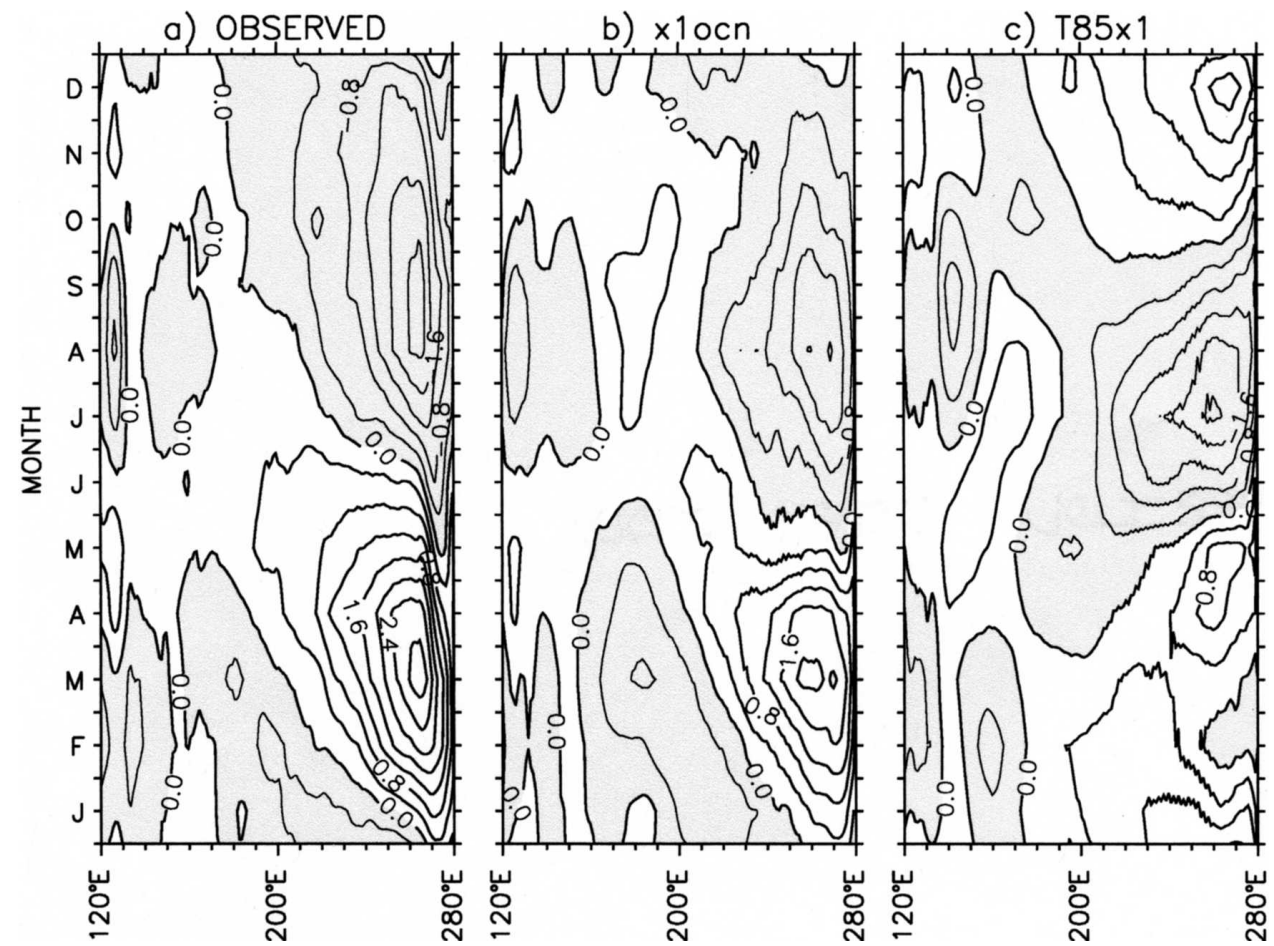

FIG. 13. Mean seasonal cycle of monthly (plotted at the middle of each month) equatorial Pacific SST anomaly from (a) observations, (b) x1ocn (2000-04), and (c) T85x1. The model solutions and observations are averaged between $0.8^{\circ} \mathrm{S}-0.8^{\circ} \mathrm{N}$ and $1^{\circ} \mathrm{S}-1^{\circ} \mathrm{N}$, respectively. The contour interval is $0.4^{\circ} \mathrm{C}$, and shading (thin lines) indicates negative anomalies.

cold bias is important for achieving a representative EUC and a stable solution (Yeager et al. 2006). In some preliminary coupled model configurations, central $\mathrm{Pa}-$ cific SST was very close to the observed during the early stages of integration, but an excess of local precipitation overly stabilized the upper ocean, trapping more heat and further increasing SST and rainfall. In one case after $50 \mathrm{yr}$ this positive feedback was continuing with the central Pacific more than $1^{\circ} \mathrm{C}$ too warm and much too fresh near the surface. A symptom of this situation is a very flat EUC whose core remained at about $90 \mathrm{~m}$ across the entire Pacific. A remnant of this problem appears to be evident in the reduced slope of the EUC core in T85x1, and even more so in T42x1. Using the depth of the core at the date line as a quantitative measure of this behavior; the observations (dotted traces in Fig. 10) and x1ocn give about $180 \mathrm{~m}$, while the two coupled models give 150 and $140 \mathrm{~m}$, respectively. The reduced rainfall in T42x1/ALL would be expected to improve the situation, and indeed this depth in Fig. 10e is about $180 \mathrm{~m}$.

\section{b. Seasonal cycles}

The mean seasonal cycle of SST anomalies across the Pacific from observations, forced $\mathrm{x} 1 \mathrm{ocn}$, and coupled
T85x1 are shown in Fig. 13. The observations are characterized by a $>2.8^{\circ} \mathrm{C}$ maximum in March and a $<-2.0^{\circ} \mathrm{C}$ minimum in September, at about $265^{\circ} \mathrm{E}$. The $\mathrm{x} 1$ ocn is similar to observations at all longitudes, but the amplitude of the annual cycle at $265^{\circ} \mathrm{E}$ is about onethird smaller, and the minimum occurs about a month sooner in August. It is disappointing to find that $\mathrm{T} 85 \mathrm{x} 1$ behaves very differently - a problem that is common to all the CCSM3 configurations and to both CCSM2 and CSM1. At $165^{\circ} \mathrm{E}$, the maximum $\left(\approx 1.6^{\circ} \mathrm{C}\right)$ is in December, with a secondary peak in April-May. Although there is a strong minimum $\left(\approx-2.0^{\circ} \mathrm{C}\right)$, its July appearance is two months early. Instead of developing a large positive anomaly from mid-December through February, the T85x1 anomaly decreases. The model's increasing anomaly over the next two months is opposite to the observed decrease. The sharp decrease in SST anomaly from May through July is the only significant signal that $\mathrm{T} 85 \mathrm{x} 1$ shares with $\mathrm{x} 1 \mathrm{con}$ and observations at $265^{\circ} \mathrm{E}$.

Experiments with CCSM2 indicate that wind coupling is a factor in its poor seasonal cycle of SST. The strategy was to replace coupled wind stress components with prescribed winds everywhere in an equatorial box from $5^{\circ} \mathrm{S}$ to $5^{\circ} \mathrm{N}$ and $105^{\circ}$ to $285^{\circ} \mathrm{E}$, with all other fluxes remaining coupled. These experiments were not 

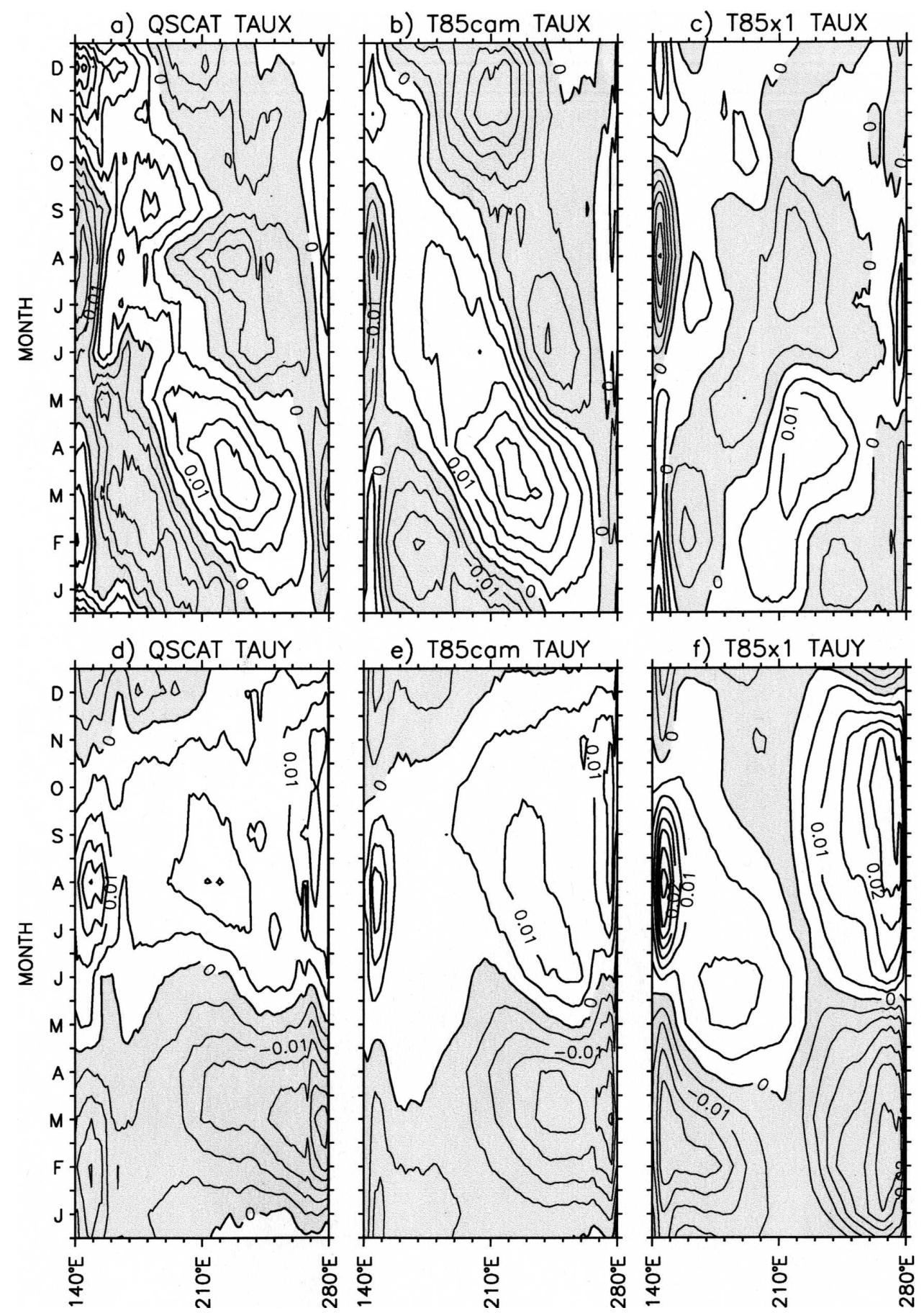

FIG. 14. Mean seasonal cycle of (top) the equatorial Pacific zonal (TAUX) and (bottom) meridional (TAUY) wind stress anomaly from (a), (d) QSCAT, (b), (e) T85cam, and (c), (f) T85x1. QSCAT and $\mathrm{T} 85 \times 1$ are averaged between $0.94^{\circ} \mathrm{S}$ and $0.94^{\circ} \mathrm{N}$. The T85atm distributions are on the atmospheric grid and represent averages for $1.4^{\circ} \mathrm{S}-1.4^{\circ} \mathrm{N}$. The contour interval is $0.005 \mathrm{~N} \mathrm{~m}^{-2}$, and shading (thin lines) indicates negative anomalies.

redone using CCSM3 because the seasonal cycles of equatorial Pacific winds from uncoupled and coupled CCSM2 are very similar to those from T85 cam and T85x1, respectively. These T85 winds are shown along with QSCAT in Fig. 14. T85cam is very similar to QSCAT throughout the year in meridional wind, and from January through July in the zonal component, but this agreement is largely destroyed by coupling, with meridional 
wind in the east from February to June as the exception. Zonal winds for T85x1 have a weak seasonal cycle everywhere east of $150^{\circ} \mathrm{E}$. The interesting experimental result was that a single peak SST anomaly with about the right phase was produced whenever both wind stress components were replaced with winds either from NCEP-NCAR reanalysis, or output from uncoupled atmospheric solutions such as T85x1 (Figs. 14b and 14e). But, a double-peak structure like Fig. 13c emerged when either one of the wind components was coupled. It appears possible that small errors in zonal winds, such as the June-October zonal wind deceleration in T85cam (Fig. 14b), or its CCSM2 equivalent, are tolerable as long as equatorial winds are uncoupled. Therefore, the double peak produced with one component prescribed and the other coupled may be caused more by the coupling than the wind fields themselves.

Both the December and February extrema seen in Fig. $13 \mathrm{c}$ are greatly diminished by restoring in the PEC region, so that the seasonal cycle of SST in both $\mathrm{T} 85 \times 1 /$ ALL and T42x1/ALL is essentially single peaked in the neighborhood of $265^{\circ} \mathrm{E}$. However, there is little change in the late April peak and July minimum, whose $\approx 3$ month separation means that there is still a too strong semiannual component relative to the annual in the equatorial SST.

This evaluation of the equatorial Pacific Ocean has found that although $\mathrm{T} 85 \mathrm{x} 1$ faithfully reproduces major features of the mean temperature and salinity structure and circulation, potentially important details are not well represented, especially off the equator and at depth. Of particular concern is how to improve SST, SSS, and precipitation, while maintaining a stable solution. Perhaps more problematic with regards to generating ENSO variability are the related annual cycles of SST and winds. Both the mean and variability are remotely affected by the biases that are produced along the eastern boundaries. Developments of both the ocean and atmospheric component models and of their coupling would appear to be necessary in order to address these outstanding issues.

\section{Discussion and conclusions}

Available datasets are sufficient to detect a number of significant biases in the T85x 1 coupled model. Some of these are attributable to the ocean model and others to the atmosphere, or to coupled behavior. The same problems are evident in T42x1, so atmospheric model resolution has little effect. Some biases are more important than first expected because they exert largescale, remote influences over the coupled solution.

It is much more straightforward to diagnose biases in coupled climate models than it is to identify the cause, or to assess the global impacts. The main ingredient for the diagnosis of T85x1 biases is knowledge of nature. In the case of the large upper-ocean temperature $\left(>1^{\circ} \mathrm{C}\right)$ and salinity $(>0.5 \mathrm{psu})$ errors in the mean and seasonal cycle of T85x1, the observed SST and WOA/P are sufficient. However, as the model simulation is improved, or other aspects of model behavior are examined, the shortcomings of WOA/P (section $2 \mathrm{~b}$ ) may become problematic. The Johnson et al. (2002) data and Tropical Ocean-Global Atmosphere observing array (McPhaden et al. 1998) are viable alternatives, but only in the tropical Pacific. Aspects of ocean circulation that are known well enough to identify serious deficiencies in T85x1 include the ocean transport through Drake Passage, the path of the Gulf Stream extension and North Atlantic Current, and the strength of the South Atlantic subtropical gyre. Quantitative estimates of the strength and depth of upwelling, both equatorial and along eastern boundaries, are needed before biases in the contribution of this process to the upper-ocean heat budget can be determined.

To infer with some confidence that the atmospheric model component is responsible for a particular ocean bias in $\mathrm{T} 85 \mathrm{x} 1$, it is necessary to show that 1 ) the forcing is outside the uncertainty limits of observational estimates, 2) the forcing fields have similar errors in T85cam, and 3) the bias is absent, or at least much reduced in the forced $\mathrm{x} 1 \mathrm{ccn}$ solution. Examples where these requirements are satisfied include the large $(> \pm 1.5 \mathrm{psu}$ ) biases in tropical SSS (section 3) and the excessive Drake Passage transport (section 4). The former can be attributed to errors in precipitation, only because these errors are much larger even than the uncertainty limits suggested by the wide range of available global datasets (section 2b). Only the advent of satellite winds such as QSCAT makes it possible to be definitive about the too strong near-surface winds, with ACC strength perhaps the most serious consequence. Gyre transports are expected to be somewhat reduced for numerical reasons, but the stronger winds may be compensating, perhaps by a little too much. Similarly, the interbasin exchanges via the Indonesian Throughflow and the Bering Strait are in good agreement with observational estimates (Table 1).

Ocean biases that are found in both coupled (T85x1) and uncoupled (x1ocn) solutions most likely reflect problems with the ocean model component. The most striking examples are the positions of WBCs, which are responsible for large, midlatitude, correlated SSS and SST errors. It can only be hoped that these problems are not overly corrupting the coupled model. This assumption is supported by Magnusdottir et al. (2004), 
who found a weak response in an uncoupled atmosphere to North Atlantic SST anomalies compared to observed trends. However, their largest signal was only $-6^{\circ} \mathrm{C}$ in February and less in other months. Nevertheless, WBC positioning affects SSS and SST far more than gyre transport errors. Moving away from WBCs, the very warm and cold (by more than $6^{\circ} \mathrm{C}$ ) temperature biases at 130-m depth in Fig. 8a form within a few years. With the exception of the North Atlantic, Fig. 8c suggests that about one-half of these signals are associated with problems along eastern boundaries. The cause of the remainder should be evident from a heat budget analysis of the region, if only adequate observational estimates were available for comparison. Only the warm Pacific bias along $10^{\circ} \mathrm{N}$ forms in $\mathrm{x} 1 \mathrm{ocn}$, which is indicative of an ocean model problem.

The basic nature of spectral topography precludes a physical representation of the coastal atmosphereocean coupling. Coastal mountains make this problem particularly acute around Greenland and in the SWA, PEC, and BSC coastal regions. The west coast/eastern basin problem is amplified by the importance of winddriven (the equatorward alongshore component) upwelling in determining SST. However, the development of similar west coast SST biases in x1ocn suggests that ocean physics is also playing a role. Although there is upwelling along these coasts in both $\mathrm{T} 85 \mathrm{x} 1$ and $\mathrm{x} 1 \mathrm{con}$, it may be too weak or too shallow, and hence too warm. One possibility is that the upwelling and offshore circulation is too local, such that the offshore downwelling (as seen in the models) returns at too shallow a depth in the upper thermocline. Anomalous heating of this circulation would then continue until coastal SSTs are much too warm (Fig. 5).

The eastern boundary restoring experiments lead to the conclusion that the large biases in these regions need to be rectified because of their widespread, remote influences. In the Atlantic, these errors are largely responsible for the warm, fresh biases in the Tropics south of the equator, and the loss of a distinct ITCZ in the mean precipitation. They also lead to a small increase in the rainfall over Africa and the northwest Indian Ocean and contribute to a cold, fresh bias around $130-\mathrm{m}$ depth far to the west of the restoring. Until there is progress in reducing SWA biases, studies of the locally coupled equatorial Atlantic might utilize SWA restoring to improve the base state, including the sign of the north-south SST gradient, as can be seen in Figs. 5 and 7. In the Pacific, controlling the PEC and BSC biases through restoring improves the "double" ITCZ, the seasonal cycle of equatorial SST, and the cold, fresh bias in the western and central tropical
South Pacific. These biases also affect the warm, salty bias at $130 \mathrm{~m}$ in the North Pacific.

The x1ocn reproduces the main features of the observed mean equatorial circulation and seasonal cycle of equatorial SST in the Pacific. These are necessary capabilities for the representation of the global spatial patterns of SST variability, which are dominated by ENSO. In particular, the high spatial and temporal correlation with observations of both the first and second empirical orthogonal functions of monthly global SST and sea surface height, and of tropical Pacific SSS, are shown by Doney et al. (2003), albeit for an earlier, coarser model version of x1ocn. However, subtle ocean model problems could lead to serious consequences. For example, the eastward jets between 150- and 300-m depth and $4^{\circ}$ and $5^{\circ}$ latitude north and south exceed 10 $\mathrm{cm} \mathrm{s}^{-1}$ in the observations (Fig. 11a). They are weaker, or nonexistent, in all the model solutions, most likely because of an overly viscous ocean model. This could be a serious deficiency, because these "Tsuchiya" jets are thought to be linked to the upwelling zones along the coast of South America (McCreary et al. 2002).

Given observed SST, T85cam produces a reasonable mean and seasonal cycle of ocean forcing over the tropical Pacific, and in particular of the wind component. It is, therefore, disappointing that the seasonal cycles of SST and winds in coupled T85x1 are so poor (Figs. 13 and 14). This appears to be an example of coupled error growth over the seasonal cycle.

Of course, some model errors are compensated by others, so that a particular model improvement can degrade the overall model solution. A prime example is the cold equatorial SST pattern that at least partially compensates for the T85cam tendency to rain too much. In coupled CCSM3, a correct SST can lead to additional rainfall, a more stable water column, heating confined too near the surface, a warm SST, and even more precipitation and heating.

Acknowledgments. We are greatly indebted to all those who contributed to the observations and global datasets used in this study. Computational facilities have been provided by the National Center for Atmospheric Research (NCAR). The model development and integrations depended on the efforts of most of the staff of the Climate and Global Dynamics Division at NCAR, and the Ocean Working Group of the Community Climate System Model.

\section{REFERENCES}

Atkinson, L., T. Berger, P. Hamilton, E. Waddell, K. Leaman, and T. Lee, 1995: Current meter observations in the Old Bahama Channel. J. Geophys. Res., 100, 8555-8560. 
Beranger, K., K. Viau, B. Barnier, E. Garnier, J. M. Molines, and L. Siefridt, 1999: An Atlas of Climatic Estimates of Air-Sea Fluxes. LEGI, 19 pp. plus figures.

Boudra, D., and E. Chassignet, 1988: Dynamics of Agulhas retroflection and ring formation in a numerical model and in observations. J. Phys. Oceanogr., 18, 280-303.

Briegleb, B., C. Bitz, E. Hunke, W. Lipscomb, M. Holland, J. Schramm, and R. Moritz, 2004: Scientific description of the sea ice component in the Community Climate System Model, version three. NCAR Tech. Note TN-463+STR, 70 pp.

Bryan, F., G. Danabasoglu, N. Nakashiki, Y. Yoshida, D.-H. Kim, J. Tsutsui, and S. Doney, 2006: Response of North Atlantic thermohaline ciculation and ventilation to increasing carbon dioxide in CCSM3. J. Climate, 19, 2382-2397.

Bryden, H., and S. Imawaki, 2001: Ocean heat transport. Ocean Circulation and Climate, G. Siedler, J. Church, and J. Gould, Eds., International Geophysics Series, Vol. 77, Academic Press, 317-336.

Chin, T., R. Milliff, and W. Large, 1998: Basin-scale, highwavenumber sea surface wind fields from multiresolution analysis of scatterometer data. J. Atmos. Oceanic Technol., 15, 741-763.

Collins, W., and Coauthors, 2006a: The Community Climate System Model version 3 (CCSM3). J. Climate, 19, 2122-2143. and Coauthors, 2006b: The formulation and atmospheric simulation of the Community Atmosphere Model version 3 (CAM3). J. Climate, 19, 2144-2161.

Danabasoglu, G., 1998: On the wind-driven circulation of the uncoupled and coupled NCAR climate system ocean model. $J$. Climate, 11, 1442-1454.

— W. W. Large, J. Tribbia, P. Gent, and B. Briegleb, 2006: Diurnal coupling in the tropical oceans of CCSM3. J. Climate, 19, 2347-2365.

Deser, C., A. Capotondi, R. Saravanan, and A. Phillips, 2006: Tropical Pacific and Atlantic climate variability in CCSM3. J. Climate, 19, 2451-2481.

Dickinson, R., K. Oleson, G. Bonan, F. Hoffman, P. Thornton, M. Vertenstein, Z.-L. Yang, and X. Zeng, 2006: The Community Land Model and its climate statistics as a component of the Community Climate System Model. J. Climate, 19, 23022324.

Doney, S., W. Large, and F. Bryan, 1998: Surface ocean fluxes and water-mass transformation rates in the coupled NCAR Climate System Model. J. Climate, 11, 1420-1441.

- , S. G. Yeager, G. Danabasoglu, W. G. Large, and J. C. McWilliams, 2003: Modeling global oceanic interannual variability (1958-1997): Simulation design and model-data evaluation. NCAR Tech. Note TN-452+STR, 48 pp.

Ebuchi, N., H. Graber, and M. Caruso, 2002: Evaluation of wind vectors observed by QuikSCAT/SeaWinds using ocean buoy data. J. Atmos. Oceanic Technol., 19, 2049-2062.

Freilich, M. H., and B. A. Vanhoff, 2006: The accuracy of preliminary WindSat vector wind measurements: Comparisons with NDBC buoys and QuikSCAT. IEEE Trans. Geosci. Remote Sens. 44, 622-637.

Gent, P., and J. McWilliams, 1990: Isopycnal mixing in ocean circulation models. J. Phys. Oceanogr., 20, 150-155.

—, W. Large, and F. Bryan, 2001: What sets the mean transport through Drake Passage? J. Geophys. Res., 106, 2693-2712.

Godfrey, J., 1989: A Sverdrup model of the depth-integrated flow for the world ocean allowing for island circulations. Geophys. Astrophys. Fluid Dyn., 45, 89-112.

Gordon, A., 2001: Interocean exchange. Ocean Circulation and
Climate, G. Siedler, J. Church, and J. Gould, Eds., International Geophysics Series, Vol. 77, Academic Press, 303-314.

Gordon, C., C. Cooper, C. Senior, H. Banks, J. Gregory, T. Johns, J. Mitchell, and R. Wood, 2000: The simulation of SST, seaice extents and ocean heat transports in a version of the Hadley Centre coupled model without flux correction. Climate Dyn., 16, 147-168.

Gregg, M., T. Sanford, and D. Winkel, 2003: Reduced mixing from the breaking of internal waves in equatorial ocean waters. Nature, 422, 513-515.

Hack, J., J. Caron, G. Danabasoglu, K. Oleson, C. Bitz, and J. E. Truesdale, 2006a: CCSM-CAM3 climate simulation sensitivity to changes in horizontal resolution. J. Climate, 19, $2267-$ 2289.

S. Yeager, K. Oleson, M. Holland, J. Truesdale, and P. Rasch, 2006b: Simulation of the global hydrological cycle in the CCSM Community Atmosphere Model version 3 (CAM3): Mean features. J. Climate, 19, 2199-2221.

Hamilton, P., J. Larsen, K. Leaman, T. Lee, and E. Waddell, 2005: Transports through the Straits of Florida. J. Phys. Oceanogr., 35, 308-322.

Huffman, G. J., R. F. Adler, A. Chang, R. Ferraro, A. Gruber, A. McNab, B. Rudolf, and U. Schneider, 1997: The Global Precipitation Climatology Project (GPCP) combined precipitation dataset. Bull. Amer. Meteor. Soc., 78, 5-20.

Hurrell, J., J. Hack, A. Phillips, J. Caron, and J. Yin, 2006: The dynamical simulation of the Community Atmosphere Model version 3 (CAM3). J. Climate, 19, 2162-2183.

Johns, W., T. Shay, J. Bane, and D. Watts, 1995: Gulf Stream structure, transport, and recirculation near $68^{\circ} \mathrm{W}$. J. Geophys. Res., 100, 817-838.

Johnson, G., B. Sloyan, W. Kessler, and K. McTaggart, 2002: Direct measurements of upper ocean currents and water properties across the tropical Pacific during the 1990s. Progress in Oceanography, Vol. 52, Pergamon, 31-61.

Kalnay, E., and Coauthors, 1996: The NCEP/NCAR 40-Year Reanalysis Project. Bull. Amer. Meteor. Soc., 77, 437-471.

Kessler, W., G. Johnson, and D. Moore, 2003: Sverdrup and nonlinear dynamics of the Pacific equatorial currents. J. Phys. Oceanogr., 33, 994-1008.

Kiehl, J., and P. Gent, 2004: The Community Climate System Model, version 2. J. Climate, 17, 3666-3682.

Large, W., and S. Yeager, 2004: Diurnal to decadal global forcing for ocean and sea-ice models: The data sets and flux climatologies. NCAR Tech. Note TN-460+STR, 105 pp.

- J. McWilliams, and S. Doney, 1994: Oceanic vertical mixing: A review and a model with a nonlocal boundary layer parameterization. Rev. Geophys., 32, 363-403.

-, G. Danabasoglu, J. McWilliams, P. Gent, and F. Bryan, 2001: Equatorial circulation of a global ocean climate model with anisotropic horizontal viscosity. J. Phys. Oceanogr., 31, $518-536$.

Larsen, J., 1992: Transport and heat flux of the Florida Current at $27^{\circ} \mathrm{N}$ derived from cross-stream voltages and profiling data: Theory and observations. Philos. Trans. Roy. Soc. London, 338A, 169-236.

Levitus, S., T. Boyer, M. Conkright, D. Johnson, T. O'Brien, J. Antonov, C. Stephens, and R. Gelfeld, 1998: Introduction. Vol. 1, World Ocean Database 1998, NOAA Atlas NESDIS $18,346 \mathrm{pp}$.

- J. I. Antonov, and T. P. Boyer, 2005: Warming of the World Ocean, 1955-2003. Geophys. Res. Lett., 32, L02604, doi:10.1029/2004GL021592. 
Li, F., W. Large, W. Shaw, E. Walsh, and K. Davidson, 1989: Ocean radar backscatter relationship with near-surface winds: A case study during FASINEX. J. Phys. Oceanogr., 19, 324-353.

Liu, W., and W. Large, 1981: Determination of surface stress by Seasat-SASS: A case study with JASIN data. J. Phys. Oceanogr., 11, 1603-1611.

Magnusdottir, G., C. Deser, and R. Saravanan, 2004: The effects of North Atlantic SST and sea ice anomalies on the winter circulation in CCSM3. Part I: Main features and storm track characteristics of the response. J. Climate, 17, 857-876.

McAvaney, B., and Coauthors, 2001: Model evaluation. Climate Change 2001: The Scientific Basis, J. T. Houghton et al., Eds., Cambridge University Press, 471-523.

McCreary, J., P. Lu, and Z. Yu, 2002: Dynamics of the Pacific subsurface countercurrents. J. Phys. Oceanogr., 32, 23792404.

McPhaden, M., and Coauthors, 1998: The Tropical Ocean-Global Atmosphere observing system: A decade of progress. J. Geophys. Res., 103, 14 169-14 240.

Mechoso, C., and Coauthors, 1995: The seasonal cycle over the tropical Pacific in coupled ocean-atmosphere general circulation models. Mon. Wea. Rev., 123, 2825-2838.

Milliff, R., J. Morzel, D. Chelton, and M. Freilich, 2004: Wind stress divergence biases from rain effects on QSCAT surface wind retrievals. J. Atmos. Oceanic Technol., 21, 1216-1231.

Perry, G., P. Duffy, and N. Miller, 1996: An extended data set of river discharges for validation of general circulation models. J. Geophys. Res., 101, 21 339-21 349.

Peterson, R., and L. Stramma, 1991: Upper-level circulation in the South Atlantic Ocean. Progress in Oceanography, Vol. 26, Pergamon, 1-73.

Pickart, R., D. Torres, and R. Clarke, 2002: Hydrography of the Labrador Sea during active convection. J. Phys. Oceanogr., 32, 428-457.

Qui, B., and T. Joyce, 1992: Interannual variability in the mid- and low-latitude western North Pacific. J. Phys. Oceanogr., 22, 1062-1079.

Rayner, N., D. Parker, E. Horton, C. Folland, L. Alexander, and D. Powell, 2003: Global analyses of SST, sea ice and night marine air temperature since the late nineteenth century. $J$. Geophys. Res., 108, 4407, doi:10.1029/2002JD002670.

Reynolds, R., N. Rayner, T. Smith, D. Stokes, and W. Wang, 2002: An improved in situ and satellite SST analysis for climate. $J$. Climate, 15, 1609-1625.

Roach, A., K. Aagaard, C. Pease, S. A. Salo, T. Weingartner, V. Pavlov, and M. Kulakov, 1995: Direct measurements of transport and water properties through the Bering Strait. J. Geophys. Res., 100, $18443-18458$.

Schott, F., T. Lee, and R. Zantopp, 1988: Variability of structure and transport of the Florida Current in the period range of days to seasonal. J. Phys. Oceanogr., 18, 1209-1230.

Serreze, M., and C. Hurst, 2000: Representation of mean Arctic precipitation from NCEP-NCAR and ERA reanalyses. $J$. Climate, 13, 182-201.

Sheinbaum, J., J. Candela, A. Badan, and J. Ochoa, 2002: Flow structure and transport in the Yucatan Channel. Geophys. Res. Lett., 29, 1040, doi:10.1029/2001GL013990.

Smagorinsky, J., 1993: Some historical remarks on the use on nonlinear viscosities. Large Eddy Simulation of Complex Engineering and Geophysical Flows, B. Galperin and S. Orzag, Eds., International Geophysics Series, Cambridge University Press, 3-36.

Smith, R., and J. McWilliams, 2003: Anisotropic horizontal viscosity for ocean models. Ocean Modell., 5, 129-156.

, and P. Gent, 2004: Reference manual for the Parallel Ocean Program (POP) ocean component of the Community Climate System Model (CCSM2.0 and 3.0). Tech. Rep. LAUR-022484, LANL, 75 pp.

_, M. Maltrud, F. Bryan, and M. Hecht, 2000: Numerical simulations of the North Atlantic Ocean at $1 / 10^{\circ}$. J. Phys. Oceanogr., 30, 1532-1561.

Steele, M., R. Morley, and W. Ermold, 2001: PHC: A global ocean hydrography with a high-quality Arctic Ocean. J. Climate, 14, 2079-2087.

Stevenson, J., and P. Niiler, 1983: Upper ocean heat budget during the Hawaii-to-Tahiti shuttle experiment. J. Phys. Oceanogr., 13, 1894-1907.

Timokhov, L., and F. Tanis, 1997: Environmental Working Group Joint U.S.-Russian Atlas of the Arctic Ocean-Winter Period. Tech. Rep., Environmental Research Institute of Michigan in association with the National Snow and Ice Data Center, Ann Arbor, MI, CD-ROM.

— Russian Atlas of the Arctic Ocean-Summer Period. Tech. Rep., Environmental Research Institute of Michigan in association with the National Snow and Ice Data Center, Ann Arbor, MI, CD-ROM.

Whitworth, T., 1983: Monitoring the transport of the Antarctic Circumpolar Current at Drake Passage. J. Phys. Oceanogr., 13, 2045-2057.

- and R. Peterson, 1985: Volume transport of the Antarctic Circumpolar Current from bottom pressure measurements. $J$. Phys. Oceanogr., 15, 810-816.

Xie, P., and P. A. Arkin, 1996: Analyses of global monthly precipitation using gauge observations, satellite estimates, and numerical model predictions. J. Climate, 9, 840-858.

Yeager, S., W. Large, J. Hack, and C. Shields, 2006: The lowresolution CCSM3. J. Climate, 19, 2545-2566.

Zhang, Y. C., W. B. Rossow, A. A. Lacis, V. Oinas, and M. I. Mishchenko, 2004: Calculation of radiative flux profiles from the surface to top-of-atmosphere based on ISCCP and other global datasets: Refinements of the radiative transfer model and the input data. J. Geophys. Res., 109, D19105, doi:10.1029/2003JD004457. 